\title{
Mathematical Modelling and Simulation of a Trickle-Bed Reactor for Hydrotreating of Petroleum Feedstock
}

Ramirez-Castelan, Carlos Eduardo; Hidalgo-Vivas, Angelica; Brix, Jacob; Jensen, Anker Degn; Huusom, Jakob Kjøbsted

Published in:

International Journal of Chemical Reactor Engineering

Link to article, DOI:

10.1515/ijcre-2018-0176

Publication date:

2019

Document Version

Publisher's PDF, also known as Version of record

Link back to DTU Orbit

Citation (APA):

Ramirez-Castelan, C. E., Hidalgo-Vivas, A., Brix, J., Jensen, A. D., \& Huusom, J. K. (2019). Mathematical Modelling and Simulation of a Trickle-Bed Reactor for Hydrotreating of Petroleum Feedstock. International Journal of Chemical Reactor Engineering, 17(7). https://doi.org/10.1515/ijcre-2018-0176

\section{General rights}

Copyright and moral rights for the publications made accessible in the public portal are retained by the authors and/or other copyright owners and it is a condition of accessing publications that users recognise and abide by the legal requirements associated with these rights.

- Users may download and print one copy of any publication from the public portal for the purpose of private study or research.

- You may not further distribute the material or use it for any profit-making activity or commercial gain

- You may freely distribute the URL identifying the publication in the public portal 


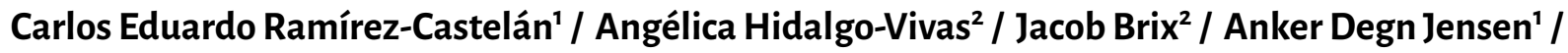 Jakob Kjobsted Huusom ${ }^{1}$
}

\section{Mathematical Modelling and Simulation of a Trickle-Bed Reactor for Hydrotreating of Petroleum Feedstock}

\author{
${ }^{1}$ Department of Chemical and Biochemical Engineering, Technical University of Denmark, S $\varnothing$ ltofts Plads, Building 229, DK- \\ 2800, Lyngby, Denmark, E-mail: jkh@kt.dtu.dk. https://orcid.org/0000-0002-1367-7235. \\ ${ }^{2}$ Haldor Tops $\varnothing$ e A/S, Haldor Topsøes Allé 1, DK-2800 Kgs, Lyngby, Denmark
}

\begin{abstract}
:
In this work, a model for a trickle-bed reactor for catalytic hydrotreating (HDT) of oil fractions is developed and simulations are performed to investigate its behavior. The model considers dynamic, one-dimensional plugflow to describe a heterogeneous, adiabatic trickle-bed reactor. It takes into consideration the main reactions present in the HDT process: hydrodesulfurization (HDS), hydrodenitrogenation (HDN), and hydrodearomatization (HDA) with a reconstructed petroleum feedstock using a practical approach of generation of pseudocomponents by dividing the boiling point curves of the feedstock. The model is solved using the method of lines with a finite difference scheme for discretization in the axial direction and simulations are performed for an industrial hydrotreating unit to evaluate the behavior of the system under different conditions and assumptions e. g. related to the linear gas velocity. A study of the dynamics is carried out to investigate the behavior of the system with a change in the sulfur compound concentration of the feed. In addition, a sensitivity analysis of the most relevant model parameters is performed.
\end{abstract}

Keywords: modelling, hydrotreating process, trickle-bed reactor

DOI: 10.1515/ijcre-2018-0176

Received: July 10, 2018; Revised: October 5, 2018; Accepted: February 2, 2019

\section{Introduction}

Heterogeneously catalyzed reactions occur in a broad range of application areas and form the basis for the manufacture of a large variety of intermediate and consumer products. Heterogeneously catalyzed gas-liquid reactions are often characterized by a high reactivity; hence, mass transport rates are highly influential (AlDahhan et al. 1997). Therefore, an essential function of a three-phase reactor is to provide contact between the phases (gas, liquid, heterogeneous catalyst). Several potential reactor arrangements exist for the processing of heterogeneously catalyzed gas-liquid reactions e. g. monolith, slurry and trickle-bed reactors.

Trickle-beds are widely used reactors in the petrochemical and chemical industries, in wastewater treatment, biochemical, and electrochemical processing (Al-Dahhan et al. 1997). In the petrochemical industry, most trickle-bed reactors operate adiabatically at high temperatures and high pressures and generally involve treating organic liquids with hydrogen. Due to the characteristics of the kinetics, the reactions conducted in tricklebed reactors often require relatively high temperatures e. g. $300-380{ }^{\circ} \mathrm{C}$ (Chowdhury, Pedernera, and Reimert 2002). Moreover, elevated pressures, up to $30 \mathrm{MPa}$, are required to improve the gas solubility and the mass transfer rates (Al-Dahhan et al. 1997). The trickle flow regime prevails at relatively low gas and liquid flow rates. The liquid flows as a laminar film or rivulets over the packing particles, while the gas passes through the void space. Despite the steady state appearance of the trickle flow regime, the physical and chemical processes, when viewed on spatial scales much smaller than the reactor, are inherently unsteady (Boelhouwer 2001). In fact, the observed macroscale flow regime is attributed to various combinations of microscale flow patterns, which are the outcome of local competition between liquid and gas in the packing interstices (Melli et al. 1990; Tsochatzidis and Karabelas 1994). However, for practical purposes, a continuous gas phase and trickle-flow conditions for the liquid are often considered to move in plug flow, therefore industrial reactors are designed to minimize the risk of maldistribution. 
Trickle-bed reactors in the petrochemical industry are often used to perform highly exothermic reactions such as the hydrogenation of unsaturated hydrocarbons (Bhaskar et al. 2004). However, one of the major disadvantages of trickle-bed reactors is their poor ability to transport the heat released by the reaction. Considering the low heat capacity of the gas, the liquid is the main heat sink. In case the generated heat is not adequately distributed, hot spots may form. These hot spots may cause the catalyst particles to sinter, and/or increase coke formation, which decreases catalyst activity and surface area. This results in a reduced catalyst life span as well as an increase in operating costs. In addition, hot spots can cause serious safety problems as they can damage the reactor shell and lead to reactor temperature runaway. Undesired side reactions can be promoted due to non-uniform temperature distributions and varying residence time of the reactants (Mederos and Ancheyta 2007), and therefore a considerable excess of hydrogen is used. Such excess reduces changes in hydrogen partial pressure due to fluctuations or distribution problems and creates gas turbulence. This assists in avoiding the production of undesired components, e. g. coke that would deactivate the catalyst.

Hydrotreating of oil fractions to remove sulfur and nitrogen compounds in the diesel is an important process of petroleum refining. It is carried out in a trickle-bed reactor with adiabatic catalytic beds and quenching zones adding cold hydrogen between the beds for temperature control. In addition, one of the main issues of working with petroleum feedstocks is the complex composition. Depending on the boiling point range, oil fractions may contain from a few hundred to thousands of different components. For modelling and simulation purposes, this implies dealing with reaction networks in specific boiling point ranges. To alleviate this situation, for practical purposes, most kinetic models are based on lumps of compounds. The feedstock is represented by lumps of compounds with similar characteristics or pseudo-components, which are delimited by the feed and product specifications. According to Ho (2008), the delimitation of pseudo-components is traditionally performed by dividing the boiling point curve of the feedstock into boiling point ranges. The generation of pseudo-components is performed by dividing the boiling point curve of the feedstock into groups of hydrocarbons with similar characteristics and specific boiling point ranges, rather than making a distinction between individual molecules. In industry, the composition of petroleum feedstocks can be reported in terms of hydrocarbon types, e.g. paraffins, olefins, naphthenes and aromatics (PONA). However, Alvarez, Castañeda, and Ancheyta (2014) apply the idea of fee $\overline{\bar{d}}$ stock reconstruction for simulation purposes by developing a moleculebased simulation algorithm. The algorithm is able to capture information about reaction paths and reactivities in order to develop detailed kinetics. However, a practical approach, which is common practice in industry, is to define additional groups of compounds according to the necessity to reflect the main reactions taking place, e. g. in gas oil hydrotreating some of the main reactions involve mono-, di- and polyaromatic compounds. The properties of the pseudo-components, e.g. molecular weights, molar volumes, etc. are then considered in the reactor model. Commercial process simulators are a useful tool to work with complex petroleum assays for steady-state modelling and optimization of hydrotreating processes. Sbaaei and Ahmed (2018) propose a model for an industrial coker complex hydrotreating unit using Aspen HYSIS®. By acquiring industrial data sets and adjusting the rate expressions to match literature data, they are able to unveil the potential of commercial process simulators for predictive modelling and optimization of hydrotreating processes.

Most of the trickle-bed reactor models reported in the literature assume isothermal operation and use either a pseudo-homogeneous approach (Collins, Hess, and Akgerman 1985) or a heterogeneous model with plug flow of gas and liquid phases (El-Hisnawi 1981; Rajashekharam, Jaganathan, and Chaudhari 1998). These models have their merits since most lab-scale reactors used to study reactions kinetics are operated isothermally. However, all these investigations dealt with hydrogenation or oxidation reactions in pure or moderately concentrated organic or aqueous solutions (large excess of liquid reactant), and, hence, considered zero-order rate with respect to the liquid reactant concentration and first order with respect to dissolved gaseous reactant concentration. Liquid reactants/solvents were assumed non-volatile and the gas phase assumed to be pure at constant partial pressure of the reacting gas. Thus, the primary model variables were the dissolved liquid-phase concentrations of the gaseous reactant and the conversion of the liquid-phase reactants. The effect of partial wetting and transport of the gaseous reactant to dry external areas of the catalyst, resulting in higher rates, was studied experimentally (El-Hisnawi 1981; Ruzika and Hanika 1994; Silva, Knoechelmann, and Lucena 2006).

Non-isothermal effects and the use of a pseudo-homogeneous energy balance to calculate the temperature at any axial location was presented by Rajashekharam, Jaganathan, and Chaudhari (1998). Approximate solutions of the gas-solid catalyst level equations was also verified by numerical solution for non-linear kinetics. The earliest unsteady-state model (Yan 1980) proposed plug-flow with vapor and liquid phases assumed to be in equilibrium at the phase boundary. This model was used to predict hot spot formation during start-up of a trickle bed reactor and investigated the effect of a gas/liquid quench stream axial position on the developing hot spot. To reduce computational complexity, spatial terms were dropped in some subcases of this model to study time variation of mass transfer coefficients and enhancement in rates and selectivity for the model reaction system. These models are far from reflecting the intricacy in industrial hydrotreating applications due to two central limitations. First, they do not consider multicomponent transport and multiple reactions properly 
as pointed out by Khadilkar, Dudukovic, and Mills (1998), and secondly, they do not consider the transient behavior simultaneously.

Patil et al. (2017) studied the performance of different bed configurations of a trickle-bed reactor for hydrotreating of vacuum gas oil (VGO). Their study features an isothermal trickle-bed reactor model to evaluate conventional configurations, such as beds in series or beds in parallel, and compare with a pre-saturated one liquid flow (POLF) configuration. The application of the POLF concept to hydrotreating processes was evaluated before (Latz et al. 2008). Although, POLF reactors have a better performance at lab-scale, at industrial scale, the results might be unsatisfactory, especially for hydrotreating of VGO. Hence, the conventional configuration of trickle-bed reactor proofs to remain customary for hydrotreating applications. More recently, Feng et al. (2018) offer a study on parameter estimation for HDS of low-temperature coal tar. In their work, they are able to determine kinetic parameters for an isothermal hydrotreating unit using experimental data at bench scale. The proposed kinetic model is useful to study the effect of different variables on the HDS of low-temperature coal tar, concluding that the temperature has a significant effect on the overall HDS reaction.

Dynamic hydrotreating trickle-bed reactors models have been published in the literature. Mederos and Ancheyta (2007) proposed a dynamic trickle-bed reactor model based on the steady state model of Korsten and Hoffmann (1996), to study the behavior of a hydrotreating reactor for sulfur removal. Whilst the energy balance was taken into account, the model was solved considering a constant gas velocity throughout the reactor. Short while later, Alvarez and Ancheyta (2012) proposed a dynamic trickle-bed reactor model for hydrodemetallization of residual oil in which the gas velocity is variable over the reactor length, but made the simplification that the catalyst and the liquid behave as a single phase. Modelling the solid phase independently can be important if the heat released by the reactions taking place is very significant.

The main objective of this work is to study the general behavior of a hydrotreating unit using different operational conditions and model parameters such as inlet temperature, inlet gas velocity and mass transfer coefficients. Hence, a predictive dynamic three-phase reactor model and model-based analysis of a tricklebed reactor is proposed considering multiple reactions: hydrodesulfurization (HDS), hydrodenitrogenation (HDN) and saturation of aromatics (HDA) with pseudo-components of the feedstock comprising mono-, di-, polyaromatics and naphthenes. The static and dynamic behavior of the model is discussed in relation to an industrial case study before performing a systematic analysis of key model assumptions and the sensitivities to key model parameters and input variables. This paper is organized with the process description in Section 2 , followed by our development of the trickle-bed reactor model in Section 3. The performance of the model on an industrial application is evaluated in Section 4, where also a sensitivity and uncertainty of model inputs and parameters and their influence on the overall process performance is discussed in detail. Finally, conclusions are drawn in Section 5.

\section{Process description}

Petroleum feedstocks contain undesired organic sulfur and nitrogen compounds that can be removed by hydrotreating. In hydrotreating processes, an oil stream is fed into a fixed-bed reactor along with a gas stream rich in hydrogen. When reacted with hydrogen, organic sulfur and nitrogen yield $\mathrm{H}_{2} \mathrm{~S}$ and $\mathrm{NH}_{3}$ gas respectively. In this way, sulfur and nitrogen are removed from the oil. During the hydrotreating process, hydrogenation of aromatic compounds also takes place. Hydrocarbons are saturated, e. g. saturation of polyaromatic compounds yield diaromatic compounds, and further all the way to naphthenes. For example:

Gas and liquid flow co-currently into the reactor from the top - see Figure 1. A layer of falling liquid covers the catalyst particles in the reaction zone. The gas phase is mostly comprised by hydrogen; however, recycle gas contains other gaseous compounds such as $\mathrm{H}_{2} \mathrm{~S}, \mathrm{NH}_{3}$ and organic sulfur compounds. The liquid phase is composed of aromatic and aliphatic compounds, as well as, sulfur- and nitrogen-organic compounds. In this work, benzothiophene $(B T)$ and dibenzothiophene $(D B T)$ are used as representative organic sulfur compounds in the model, as they are easy and difficult to desulfurize respectively. The organic nitrogen compounds are represented by carbazole $(N)$. The reaction kinetics is based on the Langmuir-Hinshelwood model with partial pressures for gas phase and concentrations for the liquid and solid phases (Chowdhury, Pedernera, and Reimert 2002), which includes kinetic and adsorption parameters for each active compound of the reaction network. Hydrotreating reactions are lumped into kinetic expressions for sulfur, nitrogen and aromatic compounds. The following reactions are considered.

- Hydrodesulfurization of sulfur containing species (benzothiophene (BT) and dibenzothiophene (DBT)):

$$
3 \mathrm{H}_{2}+\mathrm{C}_{8} \mathrm{H}_{6} \mathrm{~S} \rightarrow \mathrm{C}_{8} \mathrm{H}_{10}+\mathrm{H}_{2} \mathrm{~S}
$$




$$
5 \mathrm{H}_{2}+\mathrm{C}_{12} \mathrm{H}_{8} \mathrm{~S} \rightarrow \mathrm{C}_{12} \mathrm{H}_{16}+\mathrm{H}_{2} \mathrm{~S}
$$

- Hydrogenation of nitrogen containing species (carbazole $(N)$ ):

$$
5 \mathrm{H}_{2}+\mathrm{C}_{12} \mathrm{H}_{9} \mathrm{~N} \rightarrow \mathrm{C}_{12} \mathrm{H}_{16}+\mathrm{NH}_{3}
$$

- Saturation of mono-, di- and polyaromatic compounds:

$$
\begin{gathered}
a H_{2}+b \text { Mono } \leftrightarrow \text { cNaphthene } \\
d H_{2}+e D i \leftrightarrow f M o n o \\
g H_{2}+h \text { Poly } \leftrightarrow i D i
\end{gathered}
$$
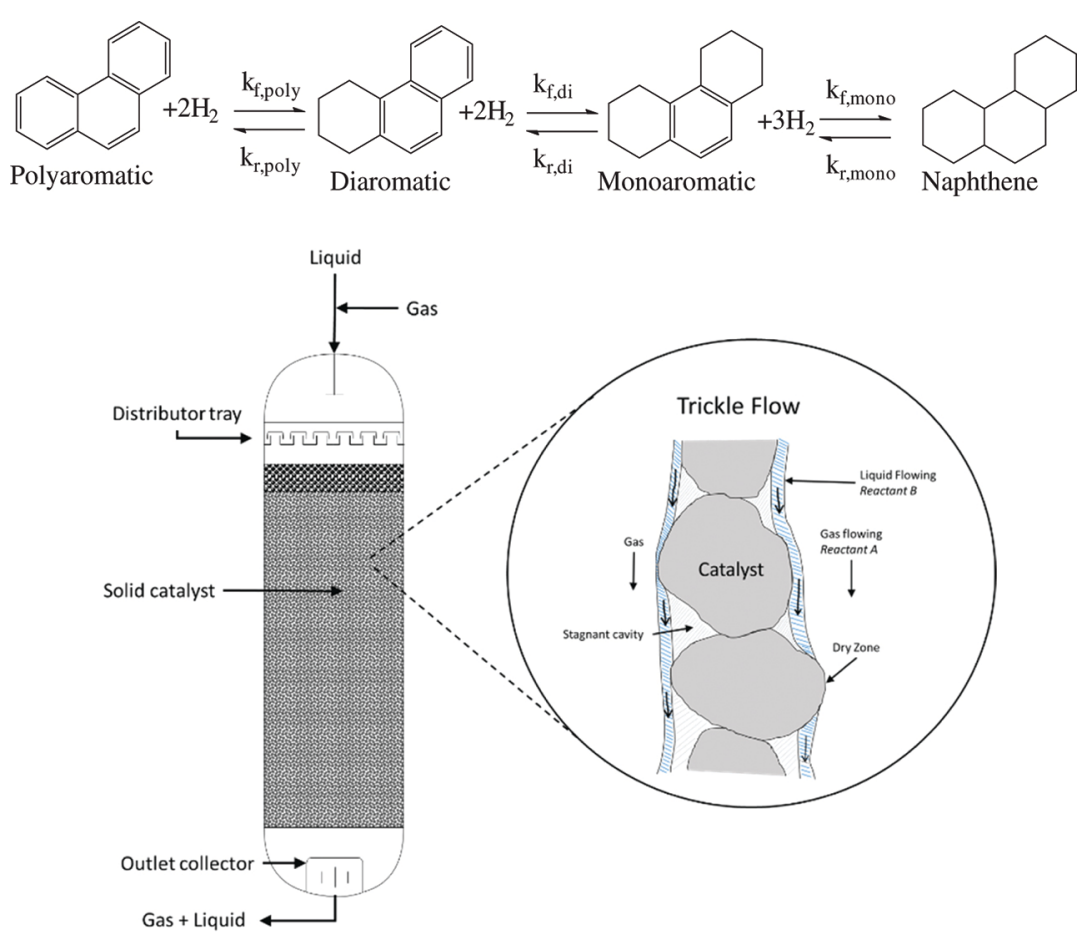

Figure 1: Schematic representation of the trickle-bed reactor.

where $a, b, c, d, e, f, g, h, i$ are stoichiometric coefficients. The stoichiometric coefficients are characteristic of the feed and can be obtained by experiments.

\section{The trickle-bed reactor model}

The trickle-bed reactor is modelled as a cylinder containing a fixed bed of catalyst through which, a mixture of gas and liquid flow cocurrently downward. The industrial reactor can be considered adiabatic (Mederos and Ancheyta 2007; Alvarez and Ancheyta 2012), and therefore without any radial transport of heat. The trickle-bed reactor model is developed from the mass and energy balance equations based on the set of assumptions listed in Table 1. For comparison, Table 1 also shows the assumptions for similar models reported in the literature.

Table 1: Assumptions for trickle-bed reactor models of respective references.

\begin{tabular}{llllll}
\hline Assumption & $\begin{array}{l}\text { Korsten } \\
\text { and }\end{array}$ & $\begin{array}{l}\text { Al- } \\
\text { Dahhan } \\
\text { et al. }\end{array}$ & $\begin{array}{l}\text { Mederos } \\
\text { and An- } \\
\text { cheyta }\end{array}$ & $\begin{array}{l}\text { Alvarez } \\
\text { and An- } \\
\text { cheyta }\end{array}$ & $\begin{array}{l}\text { This } \\
\text { work }\end{array}$ \\
& $\begin{array}{l}\text { Hoff- } \\
\text { mann }\end{array}$ & 1997 & 2007 & 2012 & \\
& 1996 & & & & \\
\hline
\end{tabular}


Gas and liquid flows are considered in axial dimension

Radial concentration and

temperature gradients are neglected

Vaporization of light ends is neglected

Variable density of liquid phase is assumed

Changes in catalyst activity with time are neglected

The process operates at constant pressure

Chemical reactions take place only at the solid catalyst surface Mass transfer is calculated by the film theory with resistance only on the liquid side

Dynamic balance for the linear gas velocity

Adiabatic model

Dynamic model

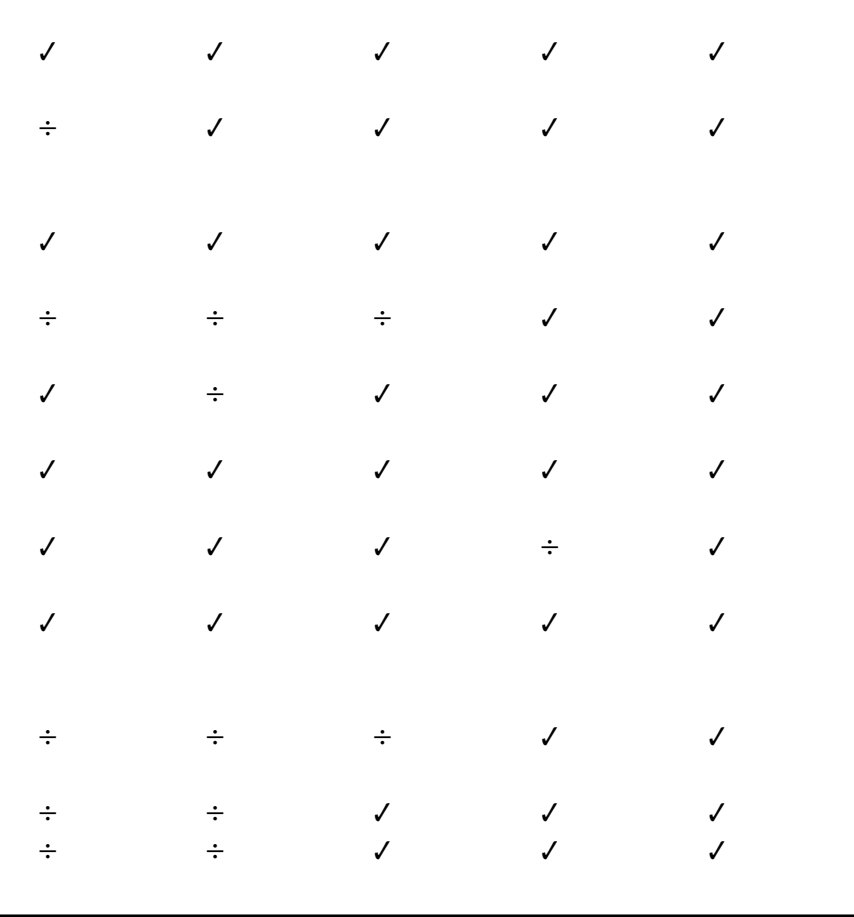

A set of assumptions of the hydrotreating trickle-bed reactor modelling approach considered in this work, are disclosed as follows:

A.1 The reactor operates in dynamic regime.

A.2 The reactor model operates adiabatically

A.3 Gas and liquid flows is co-current.

A.4 There are not radial concentration and temperature gradients.

A.5 Catalyst activity does not change with time.

A.6 Vaporization and condensation do not take place.

A.7 Constant pressure.

A.8 Mass-transfer resistance in the gas side of the gas-liquid interface is negligible.

A.9 The catalyst particles are completely wet.

A.10 Reaction takes place only in the solid phase.

A.11 Organic sulfur- and nitrogen- compounds are considered volatile.

A.12 The aromatics and naphthenes are considered nonvolatile.

A.13 The axial velocity of the gas is variable.

A.14 The gas-liquid is equal to the liquid-solid interfacial area.

A.15 HDN and HDS reactions are considered irreversible.

A.16 The effect of $\mathrm{NH}_{3}$ on the HDN reaction and organic nitrogen on the HDS reactions is negligible.

\subsection{Mass balance}

Mass-balance equations in the trickle-bed reactor are described by a set of partial differential equations (PDE's). The PDE's are obtained from a control volume $\Delta V$, that is comprised by volume fractions for gas, liquid and solid phases. The volume fractions of each phase are represented by $\varepsilon_{G} \Delta V$ for the gas, $\varepsilon_{L} \Delta V$ for the liquid and $\varepsilon_{S} \Delta V$ for the solid phase respectively. The gas and liquid flow co-currently in axial direction into the control volume through the gas and liquid void fractions. Reactants and products are transported by mass transfer between the phases and modelled as a transport from the gas phase to the liquid and from the liquid phase to the solid. Reaction takes place only in the solid phase. The mass transport phenomena are depicted in Figure 2. 


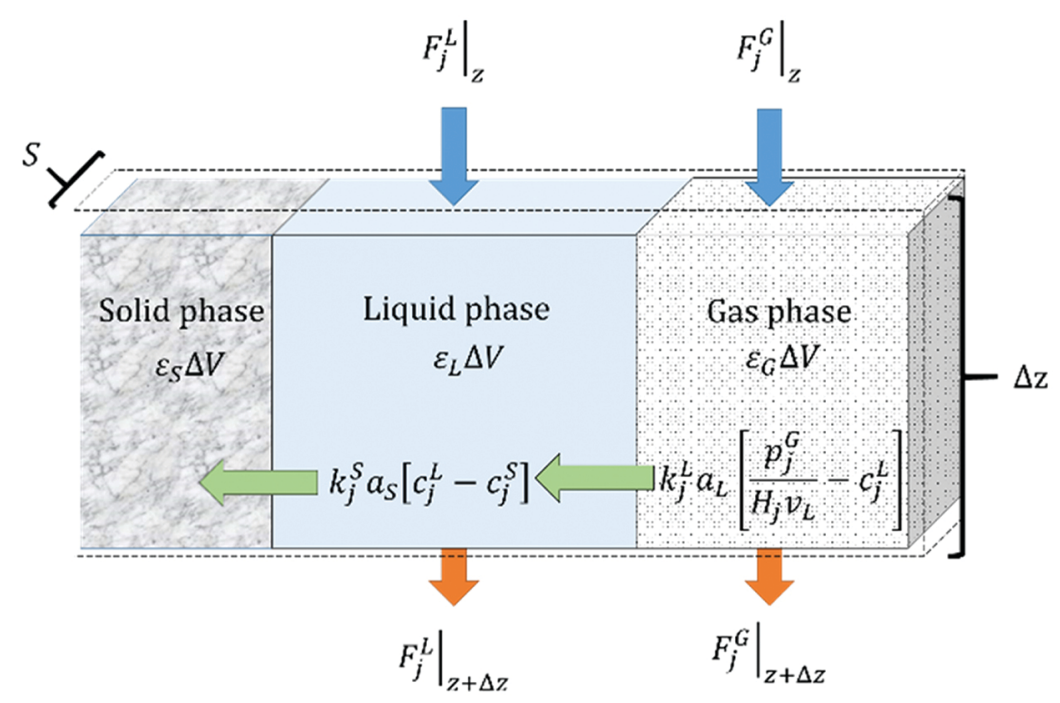

Figure 2: Mass transport from the fluid phases to the solid phase. The catalyst particles are considered completely covered by liquid.

The flows $\left(F_{j}\right)$ are expressed in moles of species $j$ in the respective phase, gas $(G)$ and liquid $(L)$ while there is no convective flow in the solid phase $(S)$. The equilibrium concentration in the film layer of species $j$ in the gas phase are expressed in terms of partial pressure $\left(p_{j}^{G}\right)$, the Henry coefficient $\left(H_{j}\right)$ and $v_{j}$ is the molar volume of species $j$ (Korsten and Hoffmann 1996). With the molar flow given as $F_{j}^{i}=u_{G} c_{j}^{i}$ for the phase $i$, the following mole balance equations are obtained:

Gas phase:

$$
\begin{aligned}
& \varepsilon_{G} \frac{\partial c_{j}^{G}}{\partial t}=-\frac{\partial\left(u_{G} c_{j}^{G}\right)}{\partial z}-k_{j}^{L} a_{L}\left[\frac{p_{j}^{G}}{H_{j} v_{j}}-c_{j}^{L}\right] \\
& j=H_{2}, H_{2} S, N H_{3}, B T, D B T
\end{aligned}
$$

Where $R$ is the gas constant, $k_{j}^{L} a_{L}$ are the specific mass transfer coefficients between the gas and the liquid phase and $S_{A}$ the cross-sectional area of the bed. Organic sulfur- and nitrogen- compounds are considered volatile. The aromatics and naphthenes are considered nonvolatile and hence are omitted from the gas phase mass balance. The axial velocity of the gas can be determined from the following equation (Alvarez and Ancheyta 2012), which is derived from the summation of all components in eq. (7):

$$
\frac{\partial u_{G}}{\partial z}=\frac{R T}{P}\left(\frac{\varepsilon_{G} P}{R T^{2}} \frac{\partial T}{\partial t}-\sum_{j} k_{j}^{L} a_{L}\left(\frac{p_{j}^{G}}{H_{j} v_{j}}-c_{j}^{L}\right)\right)+\frac{u_{G}}{T} \frac{\partial T}{\partial z}
$$

Where $T$ represents the reactor temperature.

Liquid phase:

$$
\varepsilon_{L} \frac{\partial c_{j}^{L}}{\partial t}=-u_{L} \frac{\partial c_{j}^{L}}{\partial z}+k_{j}^{L} a_{L}\left[\frac{p_{j}^{G}}{H_{j} v_{j}}-c_{j}^{L}\right]-k_{j}^{S} a_{S}\left[c_{j}^{L}-c_{j}^{S}\right]
$$

Where $\mathrm{j}=\mathrm{H}_{2}, \mathrm{H}_{2} \mathrm{~S}, \mathrm{NH}_{3}, \mathrm{BT}, \mathrm{DBT}, \mathrm{N}$, Mono-, Di, Polyaromatics and naphthenes. $\mathrm{k}_{j}^{S} a_{S}$ is the specific mass transfer coefficient between the liquid and solid phase. As the aromatics and naphthenes are considered to be nonvolatile, $k_{\text {Mono }}^{L} a_{L}=k_{D i}^{L} a_{L}=k_{\text {Poly }}^{L} a_{L}=k_{\text {Naphtenes }}^{L} a_{L}=0$ and $p_{\text {Mono }}^{G}=p_{D i}^{G}=p_{\text {Poly }}^{G}=p_{\text {Naphtenes }}^{G}=0$.

Solid phase:

$$
\varepsilon_{S} \varepsilon_{\text {pores }} \frac{\partial c_{j}^{S}}{\partial t}=k_{j}^{S} a_{S}\left[c_{j}^{L}-c_{j}^{S}\right]+\varepsilon_{S} \rho_{c a t} r_{j}{ }^{S}
$$

Where $\mathrm{j}=\mathrm{H}_{2}, \mathrm{H}_{2} \mathrm{~S}, \mathrm{NH}_{3}, \mathrm{BT}, \mathrm{DBT}, \mathrm{N}, \mathrm{Mono}-$, Di, Polyaromatics and naphthenes. $\rho_{\text {cat }}$ is the density of the catalyst and $r_{j}{ }^{S}$ is the effective reaction rate for species $j$. 
The solid phase $\left(\varepsilon_{S} \Delta V=V_{S}\right)$ is constituted by the porous solid catalyst with the pores filled with liquid and the catalyst surface completely wet. In other words, the gas and solid phase do not have contact. The volume of the solid phase is constituted partly by dense solid catalyst and the rest of the volume is pores filled with liquid, in other words, $\varepsilon_{\text {cat }} V_{S}+\varepsilon_{\text {pores }} V_{S}=V_{S}$. Here, $V_{S}$ is the volume of the solid phase, $\varepsilon_{\text {cat }}$ and $\varepsilon_{\text {pores }}$ are the volume fractions of the solid catalyst and pores respectively. These parameters have to be determined experimentally. The gas-liquid mass transfer coefficient is calculated using the following correlation (Goto and Smith 1975):

$$
k_{A}^{L} a_{L}=1.11 \times 10^{4} D_{A B}\left(\frac{G_{L}}{\mu_{L}}\right)^{0.4}\left(\frac{\mu_{L}}{\rho_{L} G_{L}}\right)^{0.5}
$$

Where $k_{A}^{L} a_{L}$ is the specific mass transfer coefficient of solute A over the gas-liquid interphase, $D_{A B}$ is the diffusion coefficient of solute $\mathrm{A}$ in solvent $\mathrm{B}, G_{L}$ is the liquid mass flux, $\mu_{L}$ and $\rho_{L}$ are the viscosity and the density of the liquid at given temperature and pressure. The liquid-solid mass transfer coefficient is calculated by the correlation (Van Krevelen and Krekels 1948):

$$
k_{A}^{S} a_{S}=1.8 D_{A B} a_{S}^{2}\left(\frac{G_{L}}{\mu_{L}}\right)^{0.5}\left(\frac{\mu_{L}}{\rho_{L} G_{L}}\right)^{1 / 3}
$$

Where $k_{A}^{S}$ is the mass transfer coefficient of solute A over the liquid-solid interphase $a_{S}$. The diffusion coefficients are obtained from the Tyn-Calus correlation (Korsten and Hoffmann 1996):

$$
D_{A B}=\frac{8.93 \times 10^{-8} V_{B}^{0.267} T}{V_{A}^{0.433} \mu_{B}}
$$

Where $\mu_{B}$ is the viscosity of the solvent $B$ (which in our case is the bulk liquid phase), $V_{B}$ is the molecular volume of the solute, and $T$ is the temperature.

\subsection{Energy balance}

Analogous to the mass transport, the energy is transported between phases during reaction. As shown in Figure 3 , this is modelled as transport from the gas phase to the liquid and from the liquid phase to the solid. This gives the following energy balance equations for the three phases:

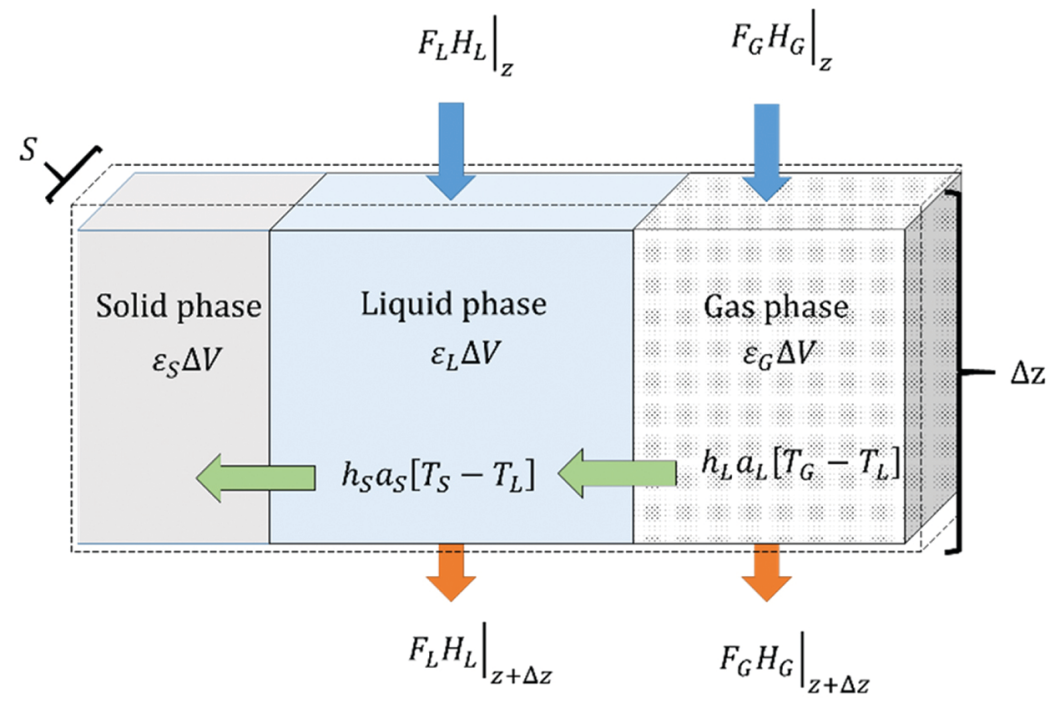

Figure 3: Energy transport from the fluid phases to the solid phase.

Gas phase:

$$
\varepsilon_{G} \rho_{G} C p_{G} \frac{\partial T_{G}}{\partial t}=-m_{G} C p_{G} \frac{\partial T_{G}}{\partial z}-h_{L} a_{L}\left(T_{G}-T_{L}\right)
$$


Liquid phase:

$$
\varepsilon_{L} \rho_{L} C p_{L} \frac{\partial T_{L}}{\partial t}=-m_{L} C p_{L} \frac{\partial T_{L}}{\partial z}+h_{L} a_{L}\left(T_{G}-T_{L}\right)-h_{S} a_{S}\left(T_{L}-T_{S}\right)
$$

Solid phase:

$$
\varepsilon_{S} \rho_{S} C p_{S} \frac{\partial T_{S}}{\partial t}=h_{S} a_{S}\left(T_{L}-T_{S}\right)-\frac{\varepsilon_{S}}{\varepsilon_{\text {pores }}} \rho_{\text {cat }} r\left(-\Delta H_{R}\right)
$$

Where $\Delta H_{R}$ is the effective heat of reaction, $h_{L}$ and $h_{S}$ are the heat transfer coefficients for the transport from the gas to the liquid and from liquid to the solid, $a_{L}$ and $a_{S}$ are the gas-liquid and liquid-solid interfacial areas respectively, and $\rho_{i}$ is the density of phase $i$ (Korsten and Hoffmann 1996). $C p_{G}$ and $C p_{L}$ are the heat capacity of the gas and the liquid respectively. Bearing in mind that the solid catalyst and its pores are filled with liquid, $C p_{S}$ is the weighted average of the heat capacities of the solid catalyst and the liquid. The heat transfer coefficient $h_{S}$ can be calculated from the following equations (Carberry 1976):

$$
h_{S}=\frac{C p_{L} j_{H}}{\left(\frac{C p_{L} \mu_{L}}{k_{\ell}}\right)^{2 / 3}}
$$

Where $\mu_{L}$ is the viscosity of the liquid, $k_{\ell}$ is the thermal conductivity of the liquid and $j_{H}$ is the $j$ factor of heat transfer that can be obtained by (Carberry 1976):

$$
j_{H}=k_{A B} \frac{\mu_{A}}{\rho_{A} D_{A B}}
$$

Where $k_{A B}$ is the mass transfer coefficient from phase A to phase $\mathrm{B}$. The same correlation is used to calculate $h_{L}$ by replacing the properties of the gas in eq. (18).

\subsection{Reaction kinetic model}

The following Langmuir-Hinshelwood type kinetic equations are used based on concentrations in the solid phase. In all rate expressions, all the concentrations refer to concentrations in the liquid trapped in the pores of the solid phase, $c_{j} S$. The superscript $S$ has been omitted in the rate expressions to give room for the exponents and $N$ stands for carbazole, which is the nitrogen organic compound. The reaction rate expressions in eqs. (19)-(23) are as reported by Chowdhury, Pedernera, and Reimert (2002) and refer to the hydrodesulfurization reaction of $\mathrm{BT}$ and $\mathrm{DBT}$ and aromatics saturation at $P^{0}=4 \mathrm{MPa}$, which are then corrected by the hydrogen partial pressure of the process, $P_{\mathrm{H} 2}$. The HDN reaction is represented by a first order kinetic expression (eq. 24). Both the HDN and HDS reactions are considered irreversible.

$$
\begin{gathered}
r_{B T}=-\frac{k_{B T} c_{B T}{ }^{1.6} c_{H_{2}}{ }^{0.56}}{1+K_{H_{2} S} \mathcal{C}_{H_{2} S}} \\
r_{D B T}=-\frac{k_{D B T} c_{D B T}^{1.6} c_{H_{2}}^{0.56}}{1+K_{H_{2} S} \mathcal{C}_{H_{2} S}} \\
r_{\text {mono }}=-k_{\mathrm{f}, \text { mono }} c_{\text {mono }}\left(\frac{P_{H_{2}}}{P^{0}}\right)^{n_{\text {mono }}}+\frac{k_{\mathrm{f}, \text { mono }}}{K_{\text {eq, mono }}} c_{\text {Naph }} \\
r_{\text {Di }}=-k_{\mathrm{f}, \text { Di }} c_{D i}\left(\frac{P_{H_{2}}}{P^{0}}\right)^{n_{d i}}+\frac{k_{\mathrm{f}, D i}}{K_{\text {eq,Di }}} c_{\text {Mono }} \\
r_{\text {Poly }}=-k_{\mathrm{f}, \text { Poly }} c_{\text {Poly }}\left(\frac{P_{H_{2}}}{P^{0}}\right)^{n_{\text {poly }}}+\frac{k_{\mathrm{f}, \text { Poly }}}{K_{\text {eq, Poly }}} c_{D i}
\end{gathered}
$$




$$
r_{N}=-k_{N} c_{N}
$$

It is assumed that the effect of $\mathrm{NH}_{3}$ on the HDN reaction and organic nitrogen on the HDS reactions is negligible. However, at high HDS and HDN conversions and/or in studies involving hydrocracking catalysts, $\mathrm{NH}_{3}$ inhibition can be very significant and should not be neglected.

\subsection{Numerical solution}

The partial differential equations (PDEs) describing the heat and mass transfer in the reactor were transformed into a set of first-order ordinary differential equations (ODEs) by discretization in the axial direction using the method of lines (Smith 1978). The independent variable time is left without discretization. The resulting ODEs become stiff in axial direction because of the nonlinearity in eqs. (19)-(24), therefore, a backwards finite difference method was used for the discretization due to its numerical stability (Iserles 2009). The initial conditions were taken from a real hydrotreating unit. The program required to calculate transport coefficients and to solve the system of ODEs simultaneously was coded in MATLAB® 2016a using 100 nodes in axial direction, the specified initial and boundary conditions, and the ode15s function with default settings. Figure 4 shows a flowchart of the implemented program to solve the model.

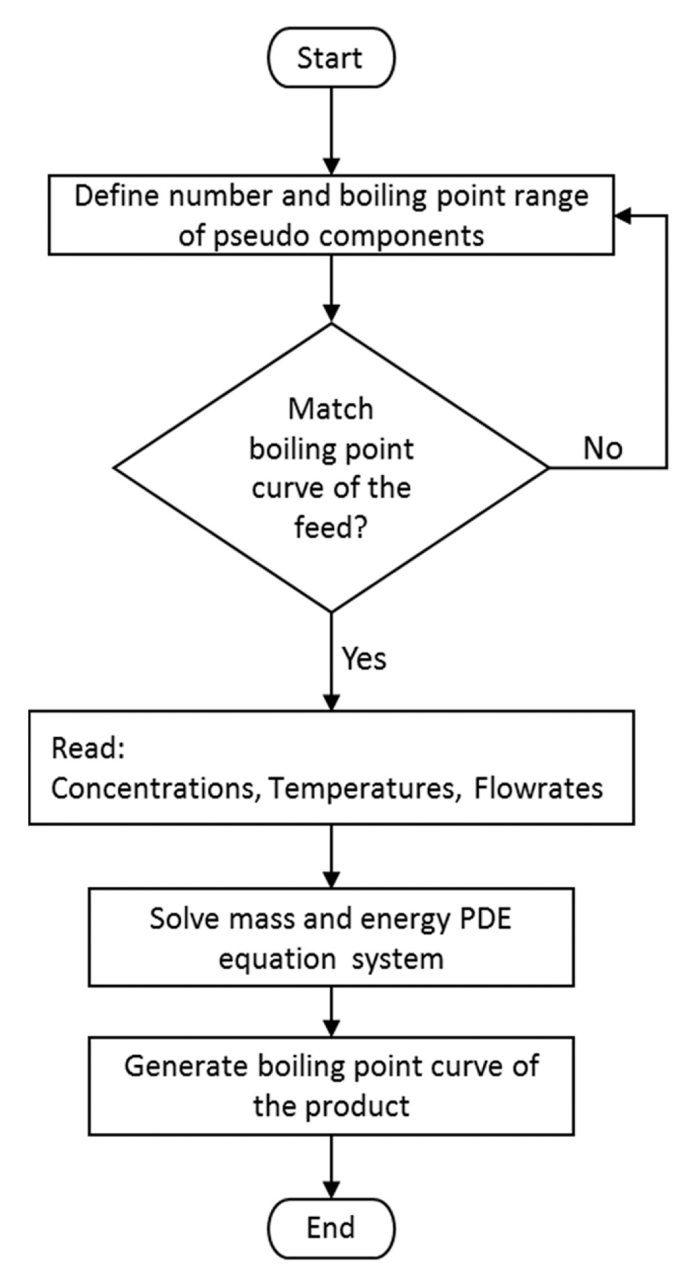

Figure 4: Flowchart of the program implemented to solve the reactor model.

\section{Results and discussion}

In order to evaluate and demonstrate the application of the model proposed in this work, a specific large-scale industrial hydrotreating reactor is considered. At the inlet, the gas and liquid feeds are assumed to be in phase equilibrium. Industrial hydrotreating units have several catalytic beds with quench zones in between; however, in this work the reactor is simulated as a single catalytic bed of 30 meters long without quench zones. This 
simplification from the real hydrotreating plant allows us to reduce the complexity of the model and study the extent of reactions at adiabatic conditions through a long bed. The hydrogen that would have been supplied in the quench zones have been added to the reactor gas feed instead. Therefore, the results of the simulation will differ from the actual industrial case; nevertheless, the behavior of the system remains consistent. In addition, the reactor is long enough such that all reaction rates approach zero towards the reactor outlet. The feed reacts with hydrogen to produce diesel with properties that fulfill mandatory requirements. The dynamic process model described in Section 3 is solved until reaching steady state with 100 nodes across the length of the unit. First, a base case simulation is performed and discussed. Secondly, the assumption of a variable gas velocity in the reactor is analyzed by comparing it to the traditional approach of a constant gas velocity in the base case. Then, a sensitivity analysis of the model parameters is performed and the sensitivity to uncertain input variables is investigated.

The base case is the hydrotreating of a feedstock with properties listed in Table 2 . Using the feedstock properties, the process simulator can be used to characterize the feed in terms of pseudo-components. The focus of the study is the aromatic groups (mono-, di-, polyaromatics). The monoaromatics are considered to have boiling point range of $220-270{ }^{\circ} \mathrm{C}$, while di- and polyaromatics are considered $270-310{ }^{\circ} \mathrm{C}$ and $310-370{ }^{\circ} \mathrm{C}$ respectively. Since other hydrocarbons have the same boiling point ranges as the aromatics of interest, using the process simulator, boiling point curves for mono-, di- and polyaromatics, by means of lumps of pseudo-components, are created such that the boiling point curve of the blend matches the boiling point curve of the actual feed. Three pseudo-components for each aromatic group were selected. Properties of each of the aromatics groups that are needed to solve the reactor model, such as molecular weight, molar volume and density, are then obtained from the process simulator and shown in Table 3 along with the respective ASTM D86 distillation curves. Figure 5 shows that the boiling point curve of the feed characterized by three lumps of pseudo-components and the one for the real feedstock are in good agreement. With all this information, the model can be solved.

Table 2: Properties of the oil feed. API stands for American Petroleum Institute gravity and IBP for initial boiling point.

\begin{tabular}{lll}
\hline Average API Gravity & & $\mathbf{3 2 . 9}$ \\
\hline IBP D86 & ${ }^{\circ} \mathrm{C}$ & 221.0 \\
$5 \% \mathrm{D} 86$ & ${ }^{\circ} \mathrm{C}$ & 248.0 \\
$10 \% \mathrm{D} 86$ & ${ }^{\circ} \mathrm{C}$ & 256.0 \\
$30 \% \mathrm{D} 86$ & ${ }^{\circ} \mathrm{C}$ & 272.0 \\
$50 \%$ D86 & ${ }^{\circ} \mathrm{C}$ & 287.0 \\
$70 \%$ D86 & ${ }^{\circ} \mathrm{C}$ & 307.0 \\
$90 \%$ D86 & ${ }^{\circ} \mathrm{C}$ & 342.0 \\
$95 \%$ D86 & ${ }^{\circ} \mathrm{C}$ & 361.0 \\
End Point D86 & ${ }^{\circ} \mathrm{C}$ & 378.0 \\
Total Nitrogen & $\mathrm{wt} \mathrm{ppm}$ & 181 \\
Sulfur & $\mathrm{wt} \%$ & 0.82 \\
Monoaromatics & $\mathrm{wt} \%$ & 17.6 \\
Diaromatics & $\mathrm{wt} \%$ & 16.0 \\
Polyaromatics & $\mathrm{wt} \%$ & 3.4 \\
\hline
\end{tabular}

Table 3: Boiling point ranges and average molecular weights of aromatic compounds.

\begin{tabular}{|c|c|c|c|c|c|}
\hline $\begin{array}{l}\text { Total density } \\
\text { IBP D86 }\end{array}$ & $\begin{array}{l}\mathrm{kg} / \mathrm{m}^{3} \\
{ }^{\circ} \mathrm{C}\end{array}$ & $\begin{array}{l}\text { Monoaromatics } \\
860.06 \\
220\end{array}$ & $\begin{array}{l}\text { Diaromatics } \\
867.53 \\
270\end{array}$ & $\begin{array}{l}\text { Polyaromatics } \\
866.02 \\
310\end{array}$ & $\begin{array}{l}\text { Naphtha } \\
778 \\
89\end{array}$ \\
\hline $5 \%$ D86 & ${ }^{\circ} \mathrm{C}$ & 227 & 274 & 312 & 101 \\
\hline $10 \%$ D86 & ${ }^{\circ} \mathrm{C}$ & 235 & 275 & 315 & 104 \\
\hline $30 \%$ D86 & ${ }^{\circ} \mathrm{C}$ & 240 & 276 & 327 & 114 \\
\hline $50 \%$ D86 & ${ }^{\circ} \mathrm{C}$ & 255 & 278 & 338 & 127 \\
\hline $70 \%$ D86 & ${ }^{\circ} \mathrm{C}$ & 265 & 291 & 350 & 142 \\
\hline $90 \%$ D86 & ${ }^{\circ} \mathrm{C}$ & 268 & 305 & 364 & 159 \\
\hline $95 \%$ D86 & ${ }^{\circ} \mathrm{C}$ & 269 & 308 & 368 & 164 \\
\hline End Point D86 & ${ }^{\circ} \mathrm{C}$ & 270 & 310 & 370 & 180 \\
\hline \multicolumn{2}{|c|}{ Average molecular weight } & 194.75 & 230.29 & 286.73 & 113.59 \\
\hline \multicolumn{2}{|c|}{ Average molar volume $\left(\mathrm{m}^{3} / \mathrm{kmol}\right)$} & 0.26 & 0.33 & 0.18 & 0.15 \\
\hline
\end{tabular}




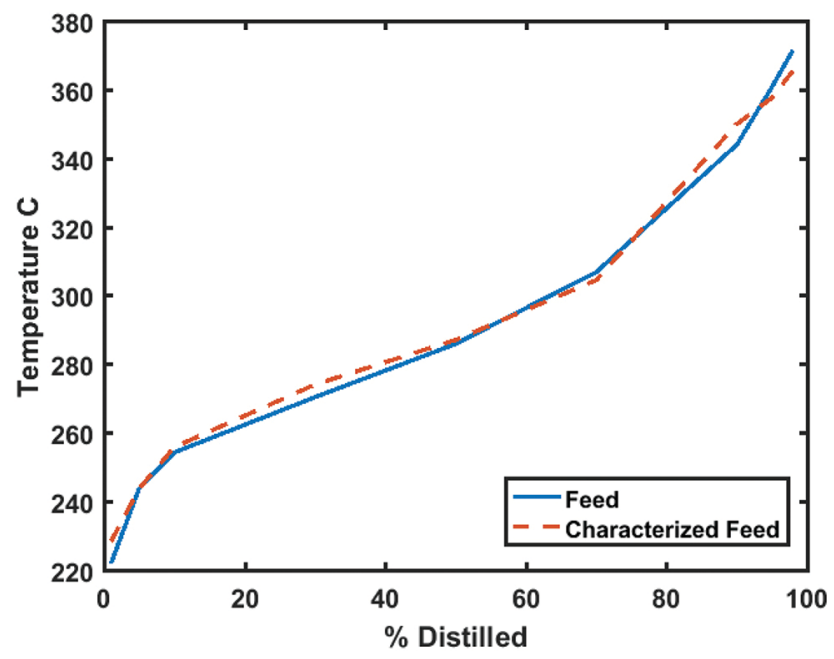

Figure 5: Comparison of the D86 boiling point curves between the feed and the characterized feed in terms of mono-, di, and polyaromatics excluding $\mathrm{H}_{2}, \mathrm{H}_{2} \mathrm{~S}$ and $\mathrm{NH}_{3}$.

In the base case, the aromatics yielded from the reactions are assumed the same as the ones defined in the feed characterization initially. The naphthenes are considered to be in the naphtha pool. The amount of hydrogen in the feed is approximately 5 times more than that stoichiometrically required. It is common practice to use a significant hydrogen excess in order to ensure sufficient hydrogen available at the catalyst surface, minimize formation of coke and facilitate removal of the generated heat. The inlet conditions are given in Table 4, stoichiometric coefficients for the reaction (1)-(6) given in Table 5 as well as the constants for the rate of reaction expressions (16)-(21), in which the forward kinetic constants are those reported by Chowdhury, Pedernera, and Reimert (2002). However, in their work, the polyaromatics concentration at the outlet is higher than in the inlet, whilst the data obtained from the plant indicate that the concentration of polyaromatics is lower. Therefore, the value of the equilibrium constants are substituted by those reported by Alvarez-Majmutov and Chen (2014) to reflect consumption of polyaromatics. Reported values of heats of reactions are given in Table 7.

Table 4: Process input parameters and specifications. Values marked with ${ }^{\text {a }}$ are taken from Pro/II.

\begin{tabular}{|c|c|}
\hline $\mathrm{T}_{\text {Gas inlet }}$ & $330^{\circ} \mathrm{C}$ \\
\hline $\mathrm{T}_{\text {Liquid inlet }}$ & $330^{\circ} \mathrm{C}$ \\
\hline $\mathrm{T}_{\text {Solid inlet }}$ & $330^{\circ} \mathrm{C}$ \\
\hline$a_{L}, a_{s}$ & $3540 \mathrm{~m}^{2} / \mathrm{m}^{3}$ \\
\hline$\rho_{\text {cat }}$ & $875 \mathrm{~kg} / \mathrm{m}^{3}$ \\
\hline $\mathrm{P}$ & $8.4 \mathrm{MPa}$ \\
\hline Inlet gas flowrate & $76 \times 10^{4} \mathrm{~kg} / \mathrm{h}$ \\
\hline Inlet liquid flowrate & $237 \times 10^{4} \mathrm{~kg} / \mathrm{h}$ \\
\hline$C p_{G}{ }^{a}$ & $0.917 \mathrm{kcal} / \mathrm{kg}^{\circ} \mathrm{C}$ \\
\hline$C p_{L}^{a}$ & $0.722 \mathrm{kcal} / \mathrm{kg}{ }^{\circ} \mathrm{C}$ \\
\hline \multicolumn{2}{|c|}{ Inlet partial pressures $(\mathrm{Pa})$} \\
\hline $\mathrm{H}_{2}$ & $7.12 \times 10^{6}$ \\
\hline $\mathrm{H}_{2} \mathrm{~S}$ & $4.8 \times 10^{2}$ \\
\hline $\mathrm{NH}_{3}$ & 29.8 \\
\hline BT & $2.96 \times 10^{3}$ \\
\hline DBT & $5.38 \times 10^{2}$ \\
\hline \multicolumn{2}{|c|}{ Inlet concentration of bulk liquid, $\mathrm{kgmol} / \mathrm{m}^{3}$} \\
\hline $\mathrm{H}_{2}$ & $3.37 \times 10^{-1}$ \\
\hline $\mathrm{H}_{2} \mathrm{~S}$ & $2.25 \times 10^{-5}$ \\
\hline $\mathrm{NH}_{3}$ & $1.07 \times 10^{-6}$ \\
\hline BT & $5.21 \times 10^{-3}$ \\
\hline DBT & $5.07 \times 10^{-2}$ \\
\hline Carbazole & $1.14 \times 10^{-3}$ \\
\hline Monoaromatics & $7.88 \times 10^{-1}$ \\
\hline Diaromatics & $6.12 \times 10^{-1}$ \\
\hline Polyaromatics & $1.27 \times 10^{-1}$ \\
\hline Naphthenes & $8.68 \times 10^{-1}$ \\
\hline \multicolumn{2}{|c|}{ Henry constants ( $\left.\mathrm{Pa} \mathrm{m^{3 }} / \mathrm{kgmol}\right)$} \\
\hline$H_{H 2} \nu_{H 2}$ & $1.81 \times 10^{7}$ \\
\hline
\end{tabular}




\begin{tabular}{ll}
$H_{H 2 S} \nu_{H 2 S}$ & $3.61 \times 10^{7}$ \\
$H_{N H 3} \nu_{N H 3}$ & $3.61 \times 10^{7}$ \\
$H_{B T} \nu_{D B T}$ & $5.69 \times 10^{5}$ \\
$H_{D B T} \nu_{D B T}$ & $1.06 \times 10^{5}$ \\
\hline
\end{tabular}

Table 5: Stoichiometric coefficients for the saturation reaction of aromatics in eqs. (4)-(6).

\begin{tabular}{lllllllll}
\hline$a$ & $b$ & $c$ & $d$ & $e$ & $f$ & $g$ & $h$ & $i$ \\
\hline 3 & 1 & 1 & 2 & 1 & 1 & 2 & 1 & 1 \\
\hline
\end{tabular}

Table 6: Kinetic parameters, equilibrium constants and exponents for pressure corrections for hydrotreating reactions in eqs (19)-(24). Data reported by ${ }^{\mathrm{a}}$ Chowdhury, Pedernera, and Reimert (2002), and ${ }^{\mathrm{b}}$ Alvarez-Majmutov and Chen (2014).

\begin{tabular}{llllll}
\hline Reaction & Expression & & & & \\
HDS & $k_{\text {ads }, H_{2} S}=$ & $50,000^{a}$ & & & \\
& $k_{H D S}=$ & $2.50 \times 10^{12} \exp (-19,384 / \mathrm{T})^{a}$ & & & \\
HDN & $k_{H D N}=$ & $110 \exp (-105,000 /(\mathrm{RT})$ & & & \\
HDA & $k_{\mathrm{f}, \text { mono }}=$ & $604 \exp (-12,414 / \mathrm{T})^{\mathrm{a}}$ & $K_{\text {mono }}=$ & $7.49 \mathrm{E}-17 \exp (24,070 / \mathrm{T})^{\mathrm{b}}$ & $n_{\text {mono }}=1^{\mathrm{b}}$ \\
& $k_{\mathrm{f}, \text { } i}=$ & $850 \exp (-12,140 / \mathrm{T})^{\mathrm{a}}$ & $K_{D i}=$ & $5.56 \mathrm{E}-11 \exp (15,741 / \mathrm{T})^{\mathrm{b}}$ & $n_{d i}=0.5^{\mathrm{b}}$ \\
& $k_{\mathrm{f}, \text { } \text { oly }}=$ & $2.66 \times 10^{5} \exp (-15,170 / \mathrm{T})^{\mathrm{a}}$ & $K_{\text {Poly }}=$ & $1.05 \mathrm{E}-5 \exp (8308 / \mathrm{T})^{\mathrm{b}}$ & $n_{\text {poly }}=0.5^{\mathrm{b}}$ \\
\hline
\end{tabular}

Table 7: Heats of reaction for the reactions in HDT process given in eqs. (1) to (6).

\begin{tabular}{|c|c|c|}
\hline Reaction & $\Delta \mathrm{H}_{\mathrm{R}}\left(\mathrm{J} / \mathrm{mol}_{\mathrm{H} 2}\right)$ & Reference \\
\hline HDS & -60400 & $\begin{array}{l}\text { Chen, Mulgundmath, and Wang } \\
2011\end{array}$ \\
\hline $\mathrm{HDN}$ & -64850 & Tarhan 1983 \\
\hline $\mathrm{HDA}_{\text {mono }}$ & -100000 & $\begin{array}{l}\text { Alvarez-Majmutov and Chen } \\
2014\end{array}$ \\
\hline $\mathrm{HDA}_{\mathrm{di}}$ & -62000 & $\begin{array}{l}\text { Alvarez-Majmutov and Chen } \\
2014\end{array}$ \\
\hline $\mathrm{HDA}_{\text {poly }}$ & -32000 & $\begin{array}{l}\text { Alvarez-Majmutov and Chen } \\
2014\end{array}$ \\
\hline
\end{tabular}

\subsection{Model evaluation}

In this section, the model equations are solved using the described numerical solution strategy (Section 3.4) to obtain the axial profiles for $\mathrm{H}_{2}, \mathrm{H}_{2} \mathrm{~S}, \mathrm{NH}_{3}, \mathrm{BT}, \mathrm{DBT}, \mathrm{N}$ and the aromatics, as well as temperature profiles. In this work, the sulfur conversion $\left(x_{A r-S}\right)$ is defined as the conversion of total organic-sulfur compounds, BT and DBT combined, considering both the gas and liquid phases and as a function of the reactor length. Let the molar flowrates of the mixture of BT and DBT be $F_{A r-S}^{\text {Total }}$, then the sulfur conversion is calculated as follows:

$$
x_{A r-S(\text { Length })}=\frac{F_{A r-S, \text { inlet }}^{\text {Total }}-F_{A r-S(\text { Length })}^{\text {Total }}}{F_{A r-S, \text { inlet }}^{\text {Total }}}
$$

The steady state solution of the model for the base case provides the profiles of the components across the length of the reactor, as shown in Figure 6. The hydrogen profiles in the gas phase and liquid phase are shown in Figure 6(a). The concentration of dissolved hydrogen decays significantly within the first meters of the reactor where all the reactions take place simultaneously as soon as the feed gets in contact with the catalyst bed. This is also reflected in the temperature increase shown in Figure 6(h) and the significant increase in concentration of $\mathrm{H}_{2} \mathrm{~S}$ (Figure 6(b)). However, as the rates of reactions slow down, an increase in the hydrogen concentration in the liquid phase is observed. The excess of hydrogen in the gas phase acts as a driving force that favors the 
transport of the hydrogen into the liquid by mass transfer. Therefore, a consistent drop in the concentration of hydrogen in the gas phase is observed towards the outlet. Figure 6(b) shows the profiles of $\mathrm{H}_{2} \mathrm{~S}$ in the gas and liquid phases, where the $\mathrm{H}_{2} \mathrm{~S}$ is produced as soon as the feed gets in contact with the catalyst bed and it is then transported to the gas phase. The rapid conversion of BT and DBT (Figure 6(c) and Figure 6(d)) results in an equally rapid production of $\mathrm{H}_{2} \mathrm{~S}$ at a higher rate than the mass transfer in the initial part of the bed, which explains the peak in the dissolved $\mathrm{H}_{2} \mathrm{~S}$ concentration. The $\mathrm{H}_{2} \mathrm{~S}$ concentration in the liquid stabilizes after 10 to 15 meters of the reactor, meaning that the rate at which it is produced equals the rate it is transported to the gas phase. Figure 6(e) shows the concentration of $\mathrm{NH}_{3}$ in the gas phase and the concentration of organic nitrogen in the liquid phase. It can be observed that the organic-nitrogen is removed from the liquid phase throughout the length of the reactor. The profiles of BT are shown in Figure 6(c), where one can observe that the easy-todesulfurize organic sulfur compounds react predominantly in the first 2 to 3 meters. However, the concentration decays throughout the reactor, meaning that the reaction rate is slower towards the outlet as the reactants are depleted. Whilst both BT and DBT profiles show that the HDS reaction occurs predominantly within the first 3 to 5 meters of the reactor, it is necessary to reach very low concentrations in the liquid phase to fulfill diesel specifications, e. g. overall sulfur content $<10 \mathrm{wt} \mathrm{ppm} \mathrm{in} \mathrm{the} \mathrm{liquid.} \mathrm{Figure} \mathrm{6(f)} \mathrm{shows} \mathrm{the} \mathrm{profile} \mathrm{of} \mathrm{the} \mathrm{organic}$ sulfur content in the liquid phase, in which $10 \mathrm{wt} \mathrm{ppm}$ is reached around 5 meters of the reactor. The profiles of mono-, di-, and polyaromatics in the liquid are shown in Figure 6(g). The monoaromatics profile is constant in the first meters due to an equal conversion of diaromatics compared to the conversion of monoaromatics that lead to an increase in the concentration of naphthenes. For the rest of the reactor, HDA reactions continues at a much slower rate.
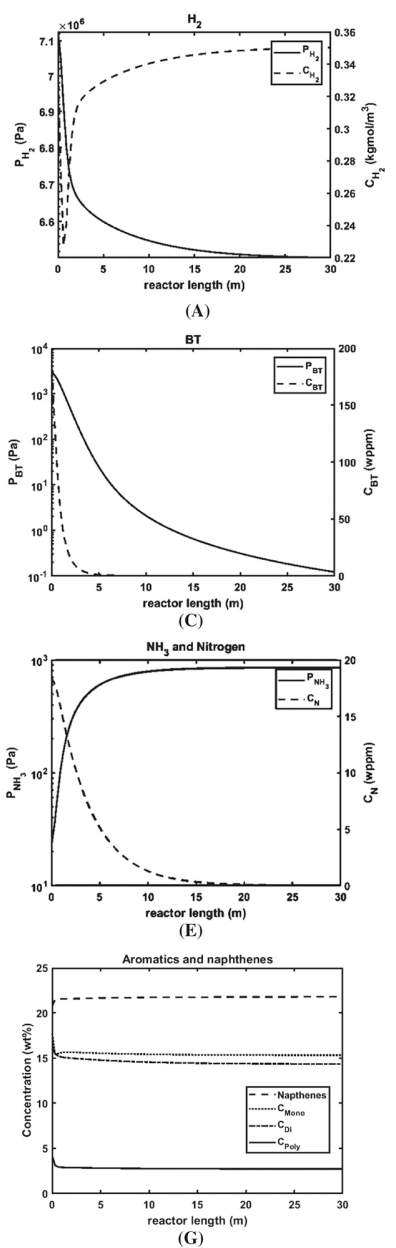

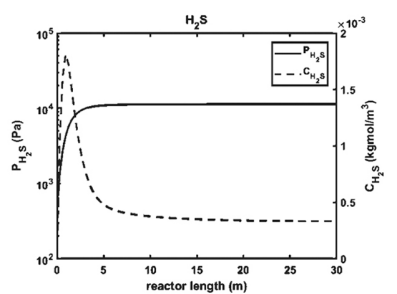

(B)
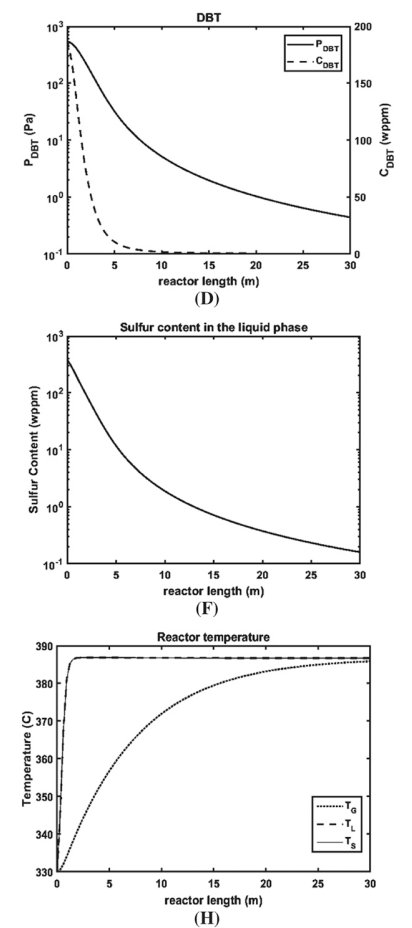

Figure 6: Concentration profiles of $\mathrm{H}_{2}, \mathrm{H}_{2} \mathrm{~S}, \mathrm{BT}, \mathrm{DBT}, \mathrm{N}(\mathrm{A})-(\mathrm{E})$. Organic sulfur content across the length of the reactor (F) and aromatic compounds across the length of the reactor $(\mathrm{G})$. and Temperature profile of gas, liquid and solid phases $(\mathrm{H})$ at steady-state.

Figure 6(h) shows the temperature profiles for gas, liquid and solid phases. The solid phase is assumed completely wetted, therefore, the heat transfer rate between solid and liquid is high, generating almost identical temperature profiles for solid and liquid phases. The temperature of the gas is clearly lower than the other two and responds slower to the generated heat from the reactions. The heat transfer resistance between the liquid and the gas phase results in a maximum temperature difference of just above $50{ }^{\circ} \mathrm{C}$ at these conditions. How- 
ever, the temperatures of all phases converge towards the same outlet value as the reaction rates approach zero. Therefore, the heat transfer catches up to equal out the difference, which implies that a thermal equilibrium is reached.

The results of the model are evaluated by comparison to the actual plant results. However, it is important to note that the results can only be compared quantitatively as the quench zones are not included in the model, where all hydrogen is introduced to the system at the reactor inlet.

The analysis of feed and product streams is displayed in Table 8, which shows the concentration in weight percent $(\mathrm{wt} \%)$ of the key components in the feed and the product to compare the model and the plant. It is evident that the model is not able to predict accurately the concentration of all the aromatics in the product. The conversion of the polyaromatics is clearly under predicted and the concentration of diaromatics is too high while that of the monoaromatics is very close to the data. The conversion of organic sulfur is slightly overestimated by the model. Overall, the model behaves as expected and a better fit can hardly be expected from a purely predictive model where all the reaction and transport coefficients are taken from literature (Chowdhury, Pedernera, and Reimert 2002; Chen, Mulgundmath, and Wang 2011). It is known that the kinetics expressions from the literature in general do not predict adequately the high conversion in the HDA reactions from the plant data.

Table 8: Concentration of aromatics in the feed and the product of the real plant and the simulation.

\begin{tabular}{lllll}
\hline & $\begin{array}{l}\text { Feed } \\
\text { Model }\end{array}$ & Plant & Product & Plant \\
\hline Sulfur wt $\%$ & 0.86 & 0.86 & $0.12 \mathrm{wppm}$ & $3.4 \mathrm{wppm}$ \\
Mono wt $\%$ & 17.6 & 17.6 & 18.9 & 18.6 \\
Di wt $\%$ & 16.0 & 16.0 & 12.1 & 3.0 \\
Poly wt $\%$ & 4.1 & 4.1 & 3.4 & 0.4 \\
\hline
\end{tabular}

The boiling point curve of the product from the model and the actual boiling point curve of the real product is displayed in Figure 7. The main difference between the model and actual distillation curves is observed in the region of 0 to $40 \%$ distilled. The model predicts a higher concentration of more volatile compounds.

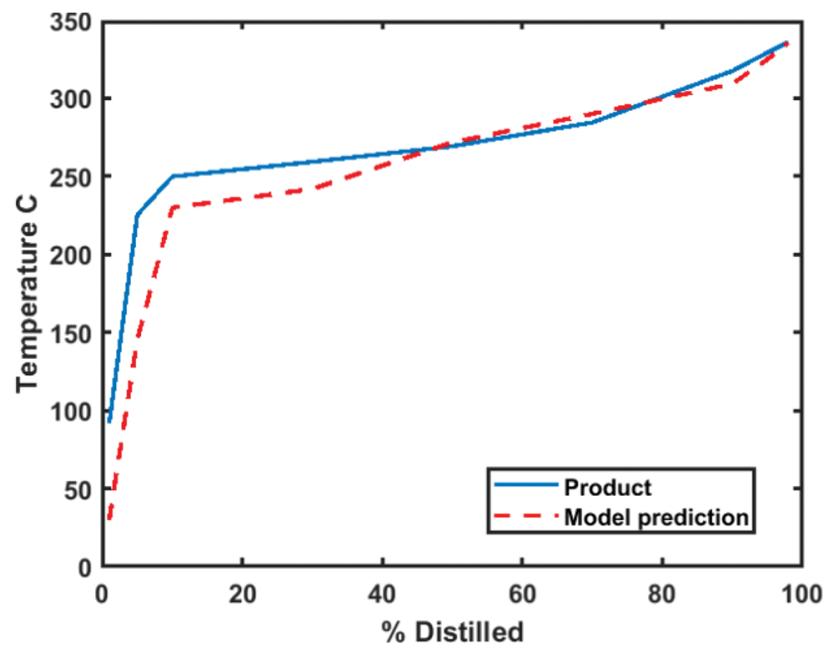

Figure 7: Comparison of the boiling point curve of the actual product and the boiling point curve for the product from the model.

This difference can be attributed to the use of pseudo-components to represent the naphthenes generated from the monoaromatics reaction.

The results of the simulations follow the trend of previous works reported by Chen, Mulgundmath, and Wang (2011) and Alvarez-Majmutov and Chen (2014) in which three aromatic lumps, i. e. polyaromatics, diaromatics and monoaromatics, are converted. However, these studies were used to account for the vaporization of aromatics in models of hydrotreating reactors and a detailed study of the aromatics concentration of the product is missing. The prediction of the concentration of aromatics throughout the reactor is determined by the selection of the HDA kinetic model. Hence, with the available kinetic model, it is challenging to reproduce the behavior of the real large-scale plant. In addition, there is a lack of experimental kinetic data of hydrogenation of complex mixtures of aromatics in literature. Therefore, a sensitivity analysis on kinetic parameters on the model is performed in Section 4.3 . 


\subsubsection{Dynamic response}

In this section, the dynamic response of the model is evaluated. In practice, the HDT unit might be subject to changes in the feed. Depending on the source of the feedstock, the concentration of total sulfur compounds will change accordingly. Hence, in this section, a change in the concentration in the difficult-to-desulfurize sulfur compounds is simulated to study the dynamic behavior of the proposed model.

At time $t=0$, a change in the concentration of difficult-to-desulfurize sulfur compounds in the liquid phase is implemented. Figure 8 shows the transient concentration profiles of DBT in the liquid phase at nine specific lengths down the reactor. These profiles display how the change in the inlet conditions propagate down through the reactor and show both the delay in the response of the system towards the outlet of the reactor and how the step change is being smoothed on the way. It is seen that it takes almost an hour before a steady outlet conditions are obtained for the sulfur content in the product.
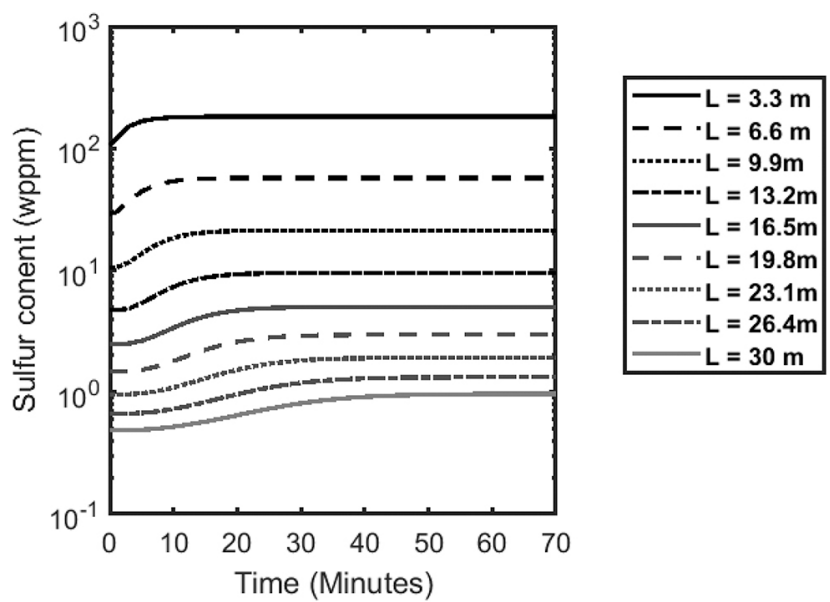

Figure 8: Dynamic profiles of concentration of DBT with a change of $+10 \%$ in the feed at time $t=0$ at different positions in the reactor.

\subsection{Comparison of a variable and constant axial gas velocity.}

Considering the large excess of hydrogen to the reactor, a constant gas velocity has often been assumed in the literature (e. g. Mederos and Ancheyta 2007). However, it can be seen from the reactions in (1) to (6), that gaseous species are consumed at different stoichiometric ratio than they are produced. Furthermore, changes in temperature and pressure along the reactor influence the gas velocity and should be taken into account. This is most conveniently done by using molar flow rates as dependent variables rather than concentrations and applying an equation of state to account for the specific gas volume. Therefore, in our model implementation, we have evaluated both, a constant axial gas velocity, equal to the inlet value, as well as variable axial gas velocity as accounted for in eq. (8). The latter implementation is the one used in the base case simulation displayed in Figure 6 . The impact of a constant linear velocity is evaluated and the results are displayed in Table 9.

Table 9: Error of the mass balance closure due to the numerical solution of the model with variable gas velocity and constant gas velocity.

\begin{tabular}{lll}
\hline & $\begin{array}{l}\text { Error Mass balance } \\
\text { Constant } \mathbf{u}_{\mathbf{G}}\end{array}$ & ${\text { Variable } \mathbf{u}_{\mathrm{G}}}$ \\
\hline No reaction & $9.3 \times 10^{-4} \%$ & \\
HDS + HDN Reactions & $0.172 \%$ & $0.169 \%$ \\
HDS + HDN +HDA reactions & $4.08 \%$ & $4.03 \%$ \\
\hline
\end{tabular}

In this work, the simulation has been tested in order to identify the error of the numerical solution. The error in the numerical solution is performed in the overall mass balance and is defined as:

$$
\text { Error }=\frac{\left(\text { mass }_{\text {in }}-\text { mass }_{\text {out }}\right)}{\text { mass }_{\text {in }}}
$$


The numerical solution is performed first with no reactions, i. e. only the gas-liquid equilibrium is achieved. Since the incoming species are already in gas-liquid equilibrium, the error with no reaction is $9.3 \times 10^{-4} \%$, which can be considered as the simulation accuracy using the proposed finite difference scheme. Then, the solution of the model considering only HDS and HDN reactions, as well as including all the reactions for the assumption of both constant and variable gas velocity. The error of the different solutions is compared in Table 9. It can be observed that the error increases when HDS and HDN are taken into account compared to the case with no reactions. One source of error can be attributed to the use of correlations and parameters taken from different sources for similar but not identical cases available in literature. Finally, when the HDA reactions are included in the solution the error in the mass balance closure increased up to $4 \%$. The considerable growth in the error is due to the definition of the pseudo-components. The pseudo-components that are obtained from the process simulator have characteristic properties such as molecular weights (Table 3) that do not necessarily reflect the aromatic hydrogenation path similar to the example in Section 2. Therefore, the use of pseudo-components generates an error that is significantly larger than the error of the numerical solution of the implementation of a constant gas velocity in contrast with a variable gas velocity. The use of pseudo-components is, however, the practical approach of simulating the properties of a real feed. The use of a variable gas velocity might be critical for other applications where the operation regime is close to stoichiometric values such as laboratory and kinetic studies.

At large-scale operation, the assumption of a constant gas velocity can be useful since the gas is already in significant excess; however, it is conceptually wrong and including a variable gas velocity equation does not increase the complexity of the model itself. Therefore, a variable axial gas velocity will be used in this work.

\subsection{Sensitivity analysis on the model parameters}

In industry, temperature control of trickle-bed reactors is crucial, not only for safety reasons, but also to ensure the quality of the products. There are many variables or physical parameters involved in the process that may affect the overall performance. Therefore, it is important to understand which are the key process variables and parameters which are most influential and which do not change the performance significantly. However, predictions using simulations are an affordable way to identify effectively the most critical variables and parameters in a process. In the case of hydrotreating, reactor temperature and sulfur content in the liquid product are the key output variables of interest.

Publicly available HDA kinetic models reported in literature do not adequately predict the plant performance in this work. Therefore, it is important to study the effect of the selection of the kinetic parameters used in HDA reactions including the effect on the HDS reaction scheme.

Sensitivity analyses are advantageous to identify the most influential parameters in complex systems on given process outputs. The Morris screening method (Morris 1991) is generally used to perform computational experiments to determine which process variables and parameters may be considered to have effects on specific model outputs that are (a) negligible, (b) linear and additive, and (c) nonlinear or involved in interactions with other parameters. This method is often used as an efficient screening method with low computational requirements to identify the most influential parameters of a model. From a practical standpoint, it allows to make a visual representation of the importance of particular values in context of the variable of interest. In this work, the model analysis includes the model parameters, which are referred to as 'factors'. The method relies on estimating the distribution of the elementary effects $(E E)$ of each factor on the $k_{t h}$ model output called $E E_{j k}$. Let us take a model of the form:

$$
\begin{aligned}
& \frac{d x}{d t}=f(x, \theta, u, t) ; \quad x(0)=x_{0} \\
& y=g(x, \theta, u, t)
\end{aligned}
$$

The elementary effect of the $i^{\text {th }}$ input factor, $\theta_{i}$, in a point $\theta^{0}$ (input space):

$$
E E_{i}^{0}=\frac{y\left(\theta_{1}^{0}, \theta_{2}^{0}, \theta_{i}^{0}+\Delta, \ldots \theta_{m}^{0}\right)-y\left(\theta^{0}\right)}{\Delta}
$$

Morris suggests calculations of $E E_{i}$ at randomly selected points in the input space ( $m$-dimensional $p$-level grid). To this end, Morris performs $E E_{i}$ calculations $r$ times following an efficient randomized sampling scheme (Morris 1991).

$$
E E_{i}^{r}=\frac{y\left(\theta_{1}^{r}, \theta_{2}^{r}, \theta_{i}^{r}+\Delta, \ldots \theta_{m}^{r}\right)-y\left(\theta^{r}\right)}{\Delta}
$$


The data analysis is based on examination of the finite distributions of elementary effects. From each $\theta_{i}$, a random sample of size $\mathrm{r}=8$ has been collected.

First, a range for each parameter is specified. Then the sampling number is defined (e. g. 50, 100, etc.) and samples are drawn from the parameter space using an appropriate sampling technique. Two of the most common sampling techniques are random sampling and Latin Hypercube sampling. In this work, Latin Hypercube sampling is used. The output from each step is a sampling matrix with $N$ number of samples and $m$ number of parameters. Then the model is evaluated for each of the elements in the sample matrix. Finally, the parameters are ranked according to the mean $\mu_{i}$ of the output and the standard deviation $\sigma_{i}$ (Morris 1991).

In our trickle-bed reactor model, the selection of the kinetic parameters of HDA reactions has a great impact in the reaction rates, which in turn influences the prediction of the concentration profiles. Similarly, the heats of reactions of HDS, HDN and HDA reactions, as well as the mass flows of gas and liquid, influence the temperature rise and therefore also the reaction rates. These are therefore considered as the parameters of interest in the sensitivity analysis with a sampling range shown in Table 10. Particularly, for the value of $\Delta \mathrm{H}_{\text {poly, }}$, there is considerably uncertainty. In our work, a value of $\Delta \mathrm{H}_{\text {poly }}=-32 \mathrm{~kJ} / \mathrm{mol}$ of $\mathrm{H}_{2}$ was used. This value is reported by Chen, Mulgundmath, and Wang (2011), and later by Alvarez-Majmutov and Chen (2014) (see Table 7) for a similar hydrogenation reactions system. However, this value is significantly lower compared to the values for common polyaromatic compounds. For instance, in the reaction scheme given in the example in Section 2, the value of $\Delta \mathrm{H}_{\text {poly }}$ for phenanthrene is $\Delta \mathrm{H}_{\text {poly }}=-60 \mathrm{~kJ} / \mathrm{mol}$ of $\mathrm{H}_{2}$. Therefore, the sampling of the value of $\Delta \mathrm{H}_{\text {poly }}$ is performed in the range of $-32 \mathrm{~kJ} / \mathrm{mol}$ of $\mathrm{H}_{2}$ to $-60 \mathrm{~kJ} / \mathrm{mol}$ of $\mathrm{H}_{2}$. The value of the pressure corrections $\mathrm{n}_{\mathrm{mono} / \mathrm{di} / \mathrm{poly}}$ is an important parameter in the model performance because the kinetic models are usually obtained from experimental data at controlled conditions that might not translate directly to a large-scale process. In addition, the pre exponential factor $A$ of the HDA forward reactions are also subject to a specific case and catalyst used, hence, included in the sensitivity analysis. From Table 6, these were found to be $\mathrm{A}_{\text {mono }}=604$ $\mathrm{m}^{3} / \mathrm{kg} \cdot \mathrm{s}, \mathrm{A}_{\mathrm{di}}=850 \mathrm{~m}^{3} / \mathrm{kg} \cdot \mathrm{s}, \mathrm{A}_{\text {poly }}=2.66 \times 10^{5} \mathrm{~m}^{3} / \mathrm{kg} \cdot \mathrm{s}$.

Table 10: Model parameters considered in the sensitivity analysis and range of sampling.

\begin{tabular}{llll}
\hline Model Parameter & Range & Model Parameter & Range \\
\hline $\mathrm{T}_{\text {in }}$ & $\pm 20 \%$ & $\mathrm{n}_{\text {mono }}$ & $\pm 50 \%$ \\
$\mathrm{~m}_{\mathrm{G}}$ & $\pm 10 \%$ & $\mathrm{n}_{\mathrm{di}}$ & $\pm 50 \%$ \\
$\mathrm{~m}_{\mathrm{L}}$ & $\pm 10 \%$ & $\mathrm{n}_{\text {poly }}$ & $\pm 50 \%$ \\
$\Delta \mathrm{H}_{\text {mono }}$ & $\pm 5 \%$ & $\mathrm{~A}_{\text {mono }}$ & $\pm 25 \%$ \\
$\Delta \mathrm{H}_{\mathrm{di}}$ & $\pm 5 \%$ & $\mathrm{~A}_{\mathrm{di}}$ & $\pm 25 \%$ \\
$\Delta \mathrm{H}_{\text {poly }}$ & {$[-32,-60] \mathrm{kJ} / \mathrm{mol}_{\mathrm{H} 2}$} & $\mathrm{~A}_{\text {poly }}$ & $\pm 25 \%$ \\
\hline
\end{tabular}

The results of the Morris analysis are shown in Figure 9 to Figure 13. According to Morris (1991), if a model parameter $(+)$ lies inside the wedge $\left({ }^{v}\right)$, then, it indicates that its effect on the variable of interest, i. e. outlet temperature, sulfur concentration, etc., is negligible. On the contrary, if the model parameter lies outside the wedge, it has a significant effect on variable of interest. The Morris screening method provides an overview of the most sensitive parameters with respect to the following variables: (1) Outlet temperature of the reactor (Figure 9), (2) organic-sulfur concentration in the liquid phase (Figure 10), (3) Concentration of monoaromatics in the liquid phase (Figure 11), (4) Concentration of di-aromatics (Figure 12) and (5) Concentration of polyaromatics (Figure 13). In order to make the plots clear, only the most significant parameters (+) are labeled.

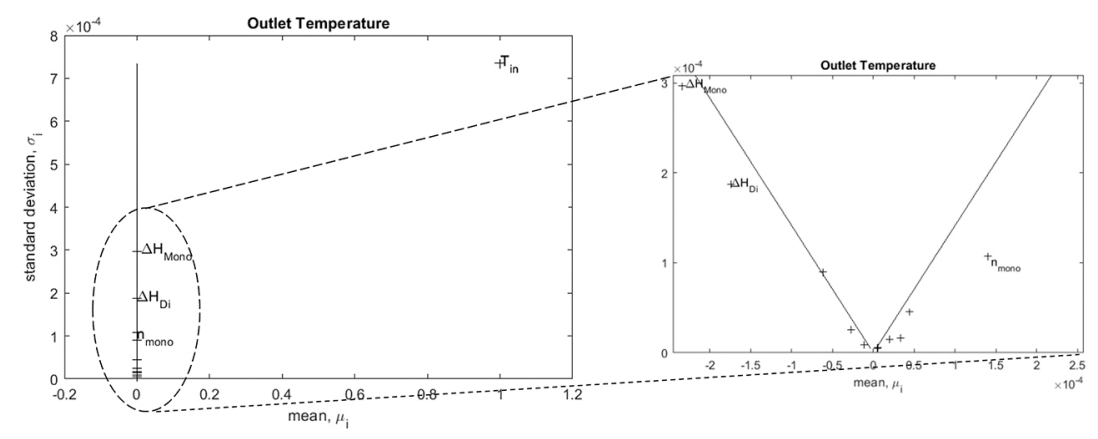

Figure 9: Morris screening method results (1). The most significant parameters to the temperature of the liquid $\left(\mathrm{T}_{\mathrm{L}}\right)$ at the outlet of the reactor. The labeled parameters outside the wedge are the most significant. 


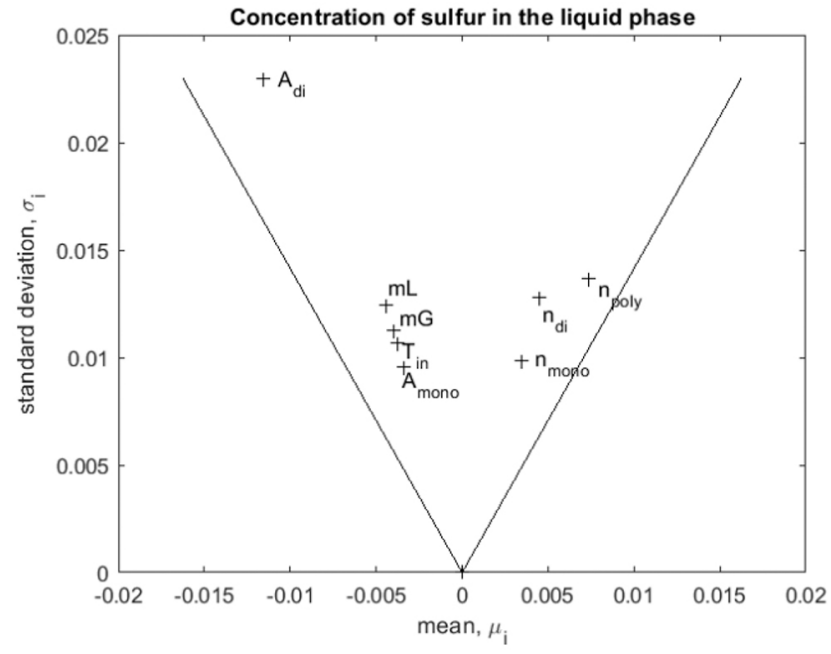

Figure 10: Morris screening method results (2). The most sensitive parameter to the concentration of organic-sulfur in the liquid phase at the outlet are the labeled parameters outside the wedge.

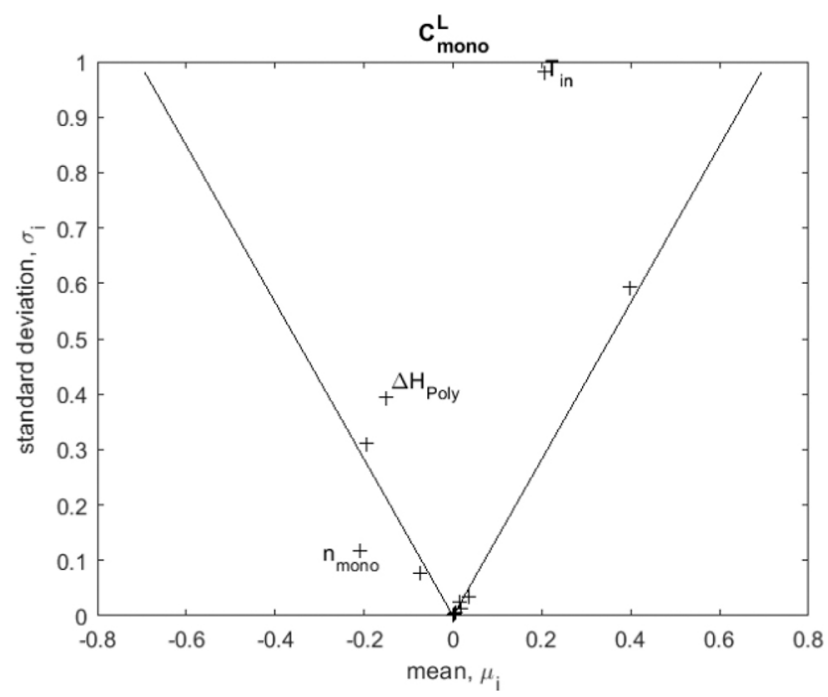

Figure 11: Morris screening method results (3). The most significant parameters to the concentration of monoaromatics in the liquid phase at the outlet are the labeled parameters outside the wedge.

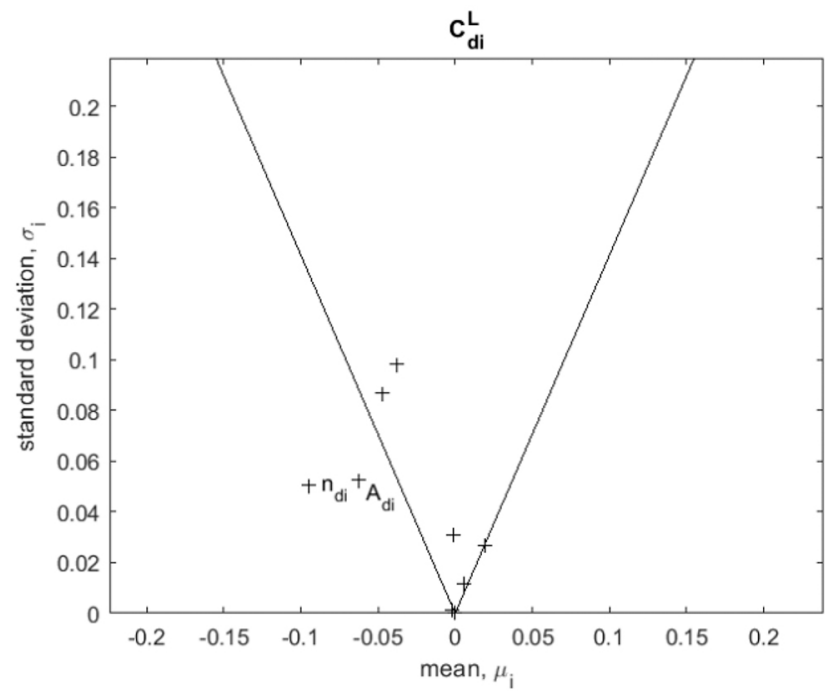

Figure 12: Morris screening method results (4). The most significant parameters to the concentration of diaromatics in the liquid phase at the outlet are the labeled parameters outside the wedge. 


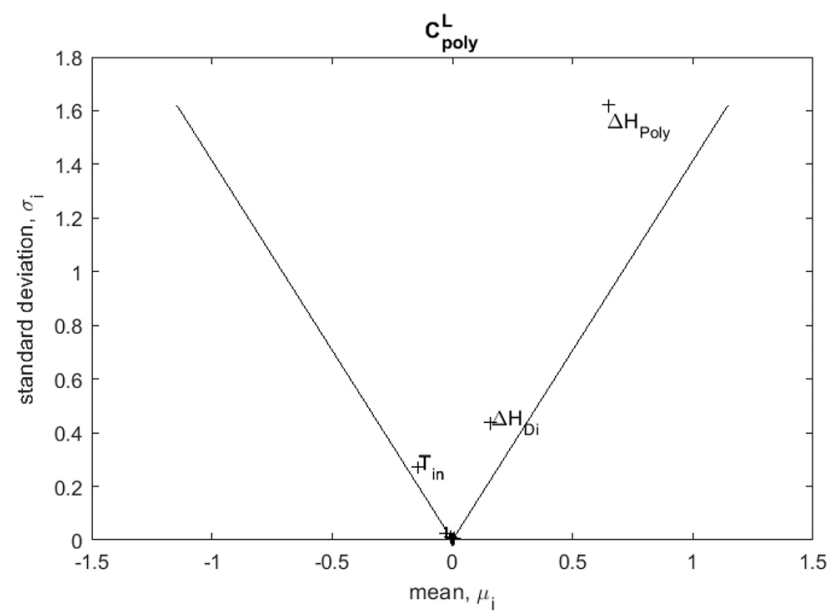

Figure 13: Morris screening method results (5). The most significant parameters to the concentration of monoaromatics in the liquid phase at the outlet are the labeled parameters outside the wedge.

In Figure 9, the Morris sensitivity analysis reveals that the critical model parameter on the outlet reactor temperature given by $T_{L}$, is the inlet temperature $\left(T_{\text {in }}\right)$ since it is significantly outside the wedge because the set of hydrotreating reactions are highly temperature dependent and release a significant amount of energy, explaining why the wedge looks like a single line. However, a closer look reveals that $\Delta \mathrm{H}_{\text {mono }}, \Delta \mathrm{H}_{\mathrm{di}}$ and $\mathrm{n}_{\text {mono }}$ also have a significant effect. The reaction path of monoaromatic compounds reacting to produce naphthenes has the highest $\Delta \mathrm{H}$, therefore a higher contribution to the temperature rise. In addition, $\mathrm{n}_{\text {mono }}$ affects directly the hydrogen pressure in the expression of the reaction rate of monoaromatics. At higher hydrogen pressures, the hydrogenation to naphthenes is favored. On the other hand, the value of $\Delta \mathrm{H}_{\mathrm{di}}$ contributes to the temperature rise because the polyaromatics generate di-aromatics. These di-aromatics generate monoaromatics and subsequently naphthenes increasing the temperature.

The Morris screening method reveals that, the organic sulfur concentration in the liquid phase is not sensitive to any of the considered parameters. The inlet temperature plays an important role in the outlet concentration of organic sulfur because HDS reaction is exothermic. However, the reactor is long enough to ensure a lowsulfur concentration in the liquid at the outlet regardless of variations in concentration of BT and DBT- type compounds in the feed. Because of this, all of the parameters included in the Morris screening method remain inside the wedge.

Figure 11 shows the sensitivity analysis of the outlet value of the concentration of monoaromatics in the liquid phase. The Morris screening method reveals that the value of $\mathrm{T}_{\text {in }}$ and $\mathrm{n}_{\text {mono }}$ are significant parameters as expected. However, the screening method portraits $\mathrm{n}_{\text {mono }}$ as a significant parameter to the concentration of monoaromatics in the outlet. This can be explained by the relationship between the excess of hydrogen and the saturation of the aromatic rings in the monoaromatics that effects the equilibrium composition. When the equilibrium of monoaromatics is shifted, it has an effect in the equilibrium of di- and polyaromatics. In addition, the outlet concentration of diaromatics is sensitive to the value of $\Delta \mathrm{H}_{\mathrm{di}}$ and $\mathrm{n}_{\mathrm{di}}$ as expected (Figure 12). It is important to note that $\mathrm{T}_{\text {in }}$ is not an influential parameter to the outlet concentrations of aromatics. If one observes Figure 6(h), the maximum temperature is reached within the first $3 \mathrm{~m}$ of the reactor, which coincides with reaching the equilibrium concentrations of aromatics.

\subsection{Model performance analysis}

In this section, the performance of the prediction acquired from the model solution is studied by evaluating the effect of the most significant parameters documented in Section 4.3. The focus is on the value of the heat of HDA

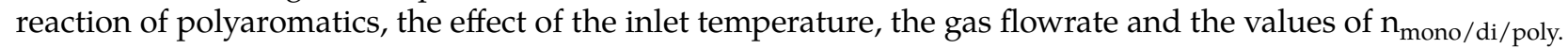

\subsubsection{Effect of inlet temperature}

In this section, results of the influence of the inlet temperature on the outlet concentrations of sulfur and aromatics is evaluated in three cases: (1) Inlet temperature of the base case $\mathrm{T}_{\text {in }}=330^{\circ} \mathrm{C}$, (2) $\mathrm{T}_{\text {in }}+20^{\circ} \mathrm{C}$ and (3) $\mathrm{T}_{\text {in }}-20$ ${ }^{\circ} \mathrm{C}$ and the results are summarized in Table 11 . The results show that at higher inlet temperature, the sulfur content at the outlet of the reactor is the same as the base case. However, the concentrations of aromatics changes 
depending on the value of $\mathrm{T}_{\mathrm{in}}$. For instance, at higher $\mathrm{T}_{\mathrm{in}}$, the monoaromatics produce more naphthenes and at the same time, di-aromatics produce less monoaromatics. In Figure 14(a), the concentration profiles are of aromatics are displayed which shows that the equilibrium of polyaromatics is only slightly affected by a higher value of the inlet temperature. However, the saturation reaction of monoaromatics to naphthenes is clearly promoted.
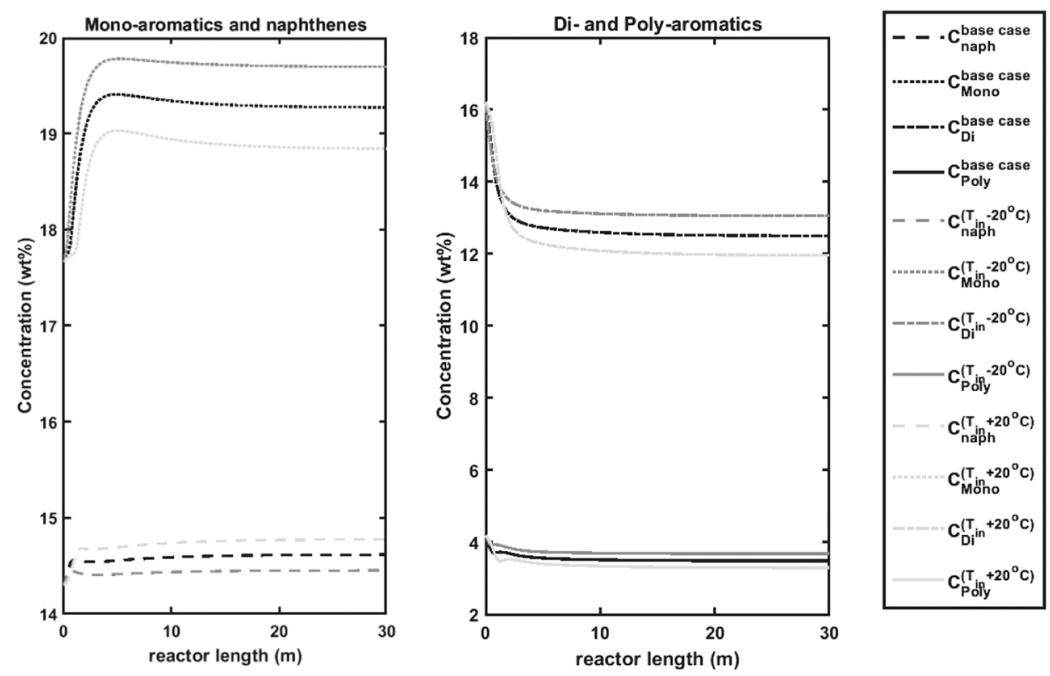

(A)

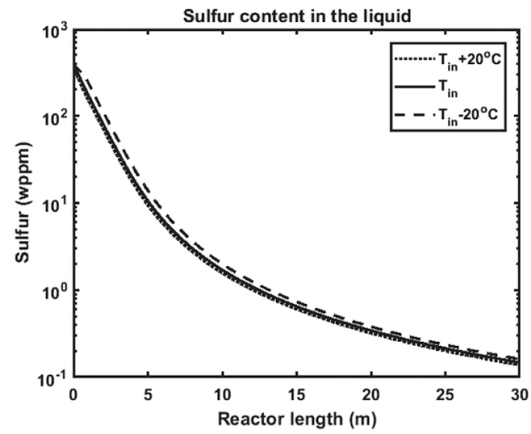

(B)

Figure 14: Simulations of (A) Concentration profiles of aromatics throughout the reactor with a variation of $\pm 20^{\circ} \mathrm{C}$ in the inlet temperature, (B) Sulfur concentration profiles throughout the reactor with a variation of $\pm 20^{\circ} \mathrm{C}$ in the inlet temperature.

Table 11: Concentration of aromatics in the feed and the product of the real plant and the simulation.

\begin{tabular}{lllll}
\hline & Product & & & \\
& & $\begin{array}{l}\text { Product } \\
\mathbf{T}_{\text {in }}+\mathbf{2 0}^{\circ} \mathbf{C}\end{array}$ & $\mathbf{T}_{\text {in }}=\mathbf{3 3 0}^{\circ} \mathbf{C}_{\text {(base case) }}$ & $\mathbf{T}_{\text {in }}-\mathbf{2 0}^{\circ} \mathbf{C}$ \\
\hline Sulfur wppm & 3.4 & 0.12 & 0.12 & 0.14 \\
Mono wt $\%$ & 18.6 & 15.6 & 18.9 & 18.6 \\
Di wt $\%$ & 3.0 & 14.9 & 12.1 & 12.7 \\
Poly wt $\%$ & 0.4 & 2.8 & 3.4 & 3.0 \\
\hline
\end{tabular}

A rather small difference in the sulfur concentration profile is also observed (Figure 14(b)). Therefore, lower values of inlet temperature have less influence in the equilibrium of aromatics and in the saturation reactions in general with the current kinetic model. 


\subsubsection{Sensitivity analysis of the correction for pressure}

The Morris screening method suggests that the value of the pressure correction has a big impact on the concentration profiles of aromatics. In this section, the sensitivity of the value of the pressure correction in equations (21)-(23) on the outlet stream of the model simulation. Since the kinetic model found in the literature predicts a lower conversion of aromatics compared to actual plant data, the analysis is performed with two cases: (a) the base case $\left(\mathrm{n}_{\text {mono }}=1, \mathrm{n}_{\mathrm{di}}=0.5\right.$ and $\left.\mathrm{n}_{\text {poly }}=0.5\right)$ in Section 2 , and (b) the solution of the model with the following values: $\mathrm{n}_{\text {mono }}=2, \mathrm{n}_{\mathrm{di}}=1$ and $\mathrm{n}_{\text {poly }}=1$. The results of the simulations at the outlet are summarized in Table 12 .

Table 12: Concentration of aromatics in the feed and the product of the real plant and the simulation.

\begin{tabular}{|c|c|c|c|}
\hline & Product (plant) $_{\text {(1) }}$ & $\begin{array}{l}\text { Product (model) } \\
\text { Case (a) } \\
\mathrm{n}_{\text {mono }}=1, \mathrm{n}_{\mathrm{di}}=0.5, \\
\mathrm{n}_{\text {poly }}=0.5\end{array}$ & $\begin{array}{l}\text { Case }(b) \\
n_{\text {mono }}=2, n_{\mathrm{di}}=1, \\
n_{\text {poly }}=1\end{array}$ \\
\hline Sulfur wppm & 3.4 & 0.12 & 0.05 \\
\hline Mono wt \% & 18.6 & 18.9 & 22.3 \\
\hline Di wt \% & 3.0 & 12.1 & 11.1 \\
\hline Poly wt \% & 0.4 & 3.4 & 2.2 \\
\hline
\end{tabular}

The results of the simulations show that the value of the correction of pressure affects the outlet concentration of aromatics. This is explained by the structure of the rate expressions. In eqs. (21)-(23), the pressure correction is related to the availability of hydrogen in terms of partial pressure. Therefore, a higher value of the pressure correction affects the reaction order that favors the forward reactions. This can be observed in Figure 15(a). In Case (b), the concentration of poly- and di- is lower at the outlet compared to Case (a), this causes an increase in concentration of mono-. However, the concentration of naphthenes is similar in both cases. Even though the kinetic model falls short to represent the plant data in terms of mono-, di- and poly-, selecting a higher value of pressure correction brings the results of the simulation closer to the real data. This is also reflected in the temperature which is considerably higher for case b, because more heat is released (Figure 15(b)). The effect is propagated to the HDS reaction, which is promoted (Figure 15(c)) across the reactor. 

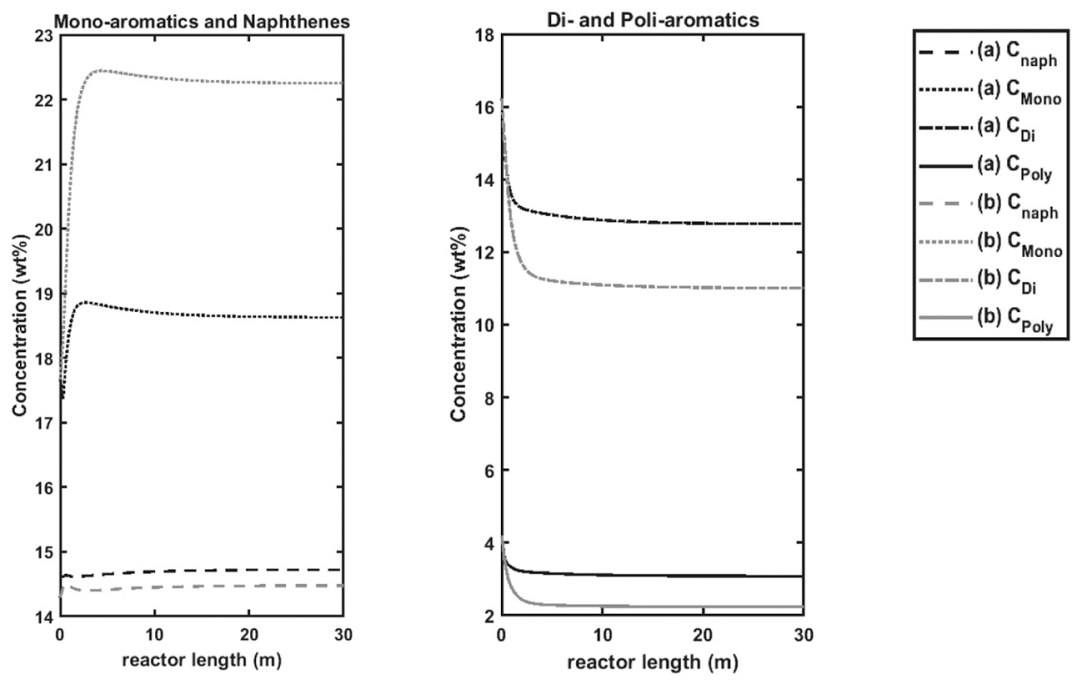

(A)

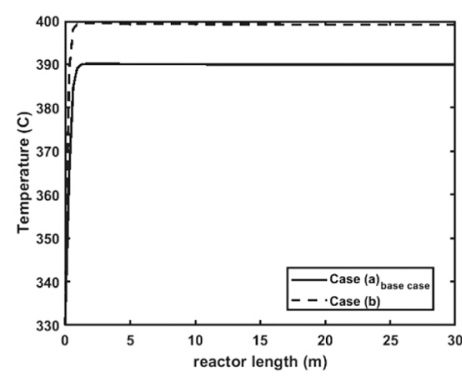

(B)

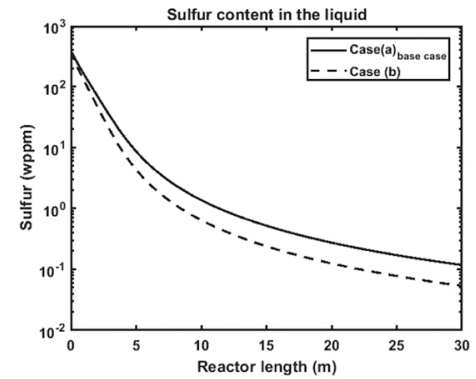

(C)

Figure 15: (A) Concentration profiles of aromatics for case (a) and case (b) across the length of the reactor. (B) Organic sulfur content in the liquid phase across the length of the reactor. (C) Temperature profiles of Cases (a) and (b).

\subsubsection{Inlet gas flowrate}

In this section, the model is evaluated using (1) the standard value of inlet gas flowrate $\left(\mathrm{m}_{\mathrm{G}}\right)$ which corresponds to 5 times the stoichiometric amount of hydrogen, (2) an intermediate value of 4.0 times the stoichiometric hydrogen and (3) 3.5 the stoichiometric hydrogen, which is the lowest value used in practice. The importance of this investigation lies on the fact that the gas is mainly composed of $\mathrm{H}_{2}$, which reacts with the liquid oil to reduce the concentration of undesired compounds such as sulfur and nitrogen. In industry, excess gas is used to ensure the required sulfur removal from the petroleum feedstock without catalyst deactivation. The recovery of unreacted hydrogen is expensive and a large recycle gas flow requires a high compression work and large equipment volumes; therefore, we investigate the influence of the hydrogen flow. Nevertheless, the model performance evaluation can be an aid for the investigation of the behavior of the system under different inlet-gas flowrate conditions. The results of the simulations for the three different flowrates mentioned earlier are summarized in Table 13. The value of the $\mathrm{H}_{2}$ /oil ratio has an effect in the organic sulfur concentration as expected. At higher $\mathrm{H}_{2}$ /oil ratio, the concentration of sulfur is affected predominantly after 5 to 6 meters of the reactor (Figure 16). On the other hand, the behavior of the aromatics is affected to a lesser degree. However, the results are still far from reproducing the data of the plant due to the kinetic model of aromatics. 


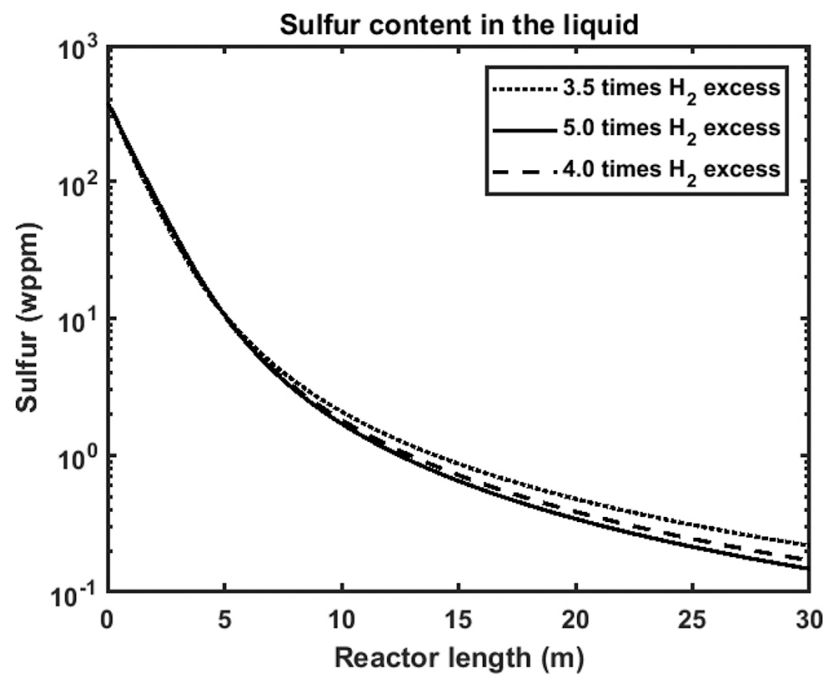

Figure 16: Sulfur content in the liquid phase across the length of the reactor (ppm) with three different $\mathrm{H}_{2} /$ oil ratios: (1) 3.5 times the stoichiometric $\mathrm{H}_{2}$, (2) 4.0 times the stoichiometric $\mathrm{H}_{2}$ and (3) 5.0 times the stoichiometric $\mathrm{H}_{2}$ (Base case).

Table 13: Concentration of aromatics in the feed and the product of the real plant and the simulation.

\begin{tabular}{lllll}
\hline & Product $_{\text {(plant) }}$ & $\begin{array}{l}\text { Product } \\
\text { (model) }\end{array}$ & & \\
& & $\mathbf{3 . 5} \mathbf{H}_{\mathbf{2}}$ excess & $\mathbf{4 . 0}_{\mathbf{2}}$ excess & $\mathbf{5 . 0}_{\mathbf{2}}$ excess $_{\text {(base case) }}$ \\
\hline Sulfur wppm & 3.4 & 0.21 & 0.17 & 0.12 \\
Mono wt $\%$ & 18.6 & 19.4 & 19.2 & 18.9 \\
Di wt \% & 3.0 & 12.6 & 12.5 & 12.1 \\
Poly wt $\%$ & 0.4 & 3.5 & 3.4 & 3.4 \\
\hline
\end{tabular}

\subsubsection{Effect of heat of reaction of aromatics}

In this subsection, the effect of the value $\Delta \mathrm{H}_{\text {poly }}$ is investigated. The study consists of the model evaluation using (1) the standard value of $\Delta \mathrm{H}_{\text {poly }}\left(-30 \mathrm{~kJ} / \mathrm{mol}_{\mathrm{H} 2}\right)$ shown in Table 8 for the base case, (2) $\mathrm{A}$ value of $\Delta \mathrm{H}_{\mathrm{poly}}$ $=-60 \mathrm{~kJ} / \mathrm{mol}_{\mathrm{H} 2}$, which is the expected value in commonly used polyaromatics in the hydrotreating reaction path, and (3) and intermediate value of $\Delta \mathrm{H}_{\text {poly }}=-45 \mathrm{~kJ} / \mathrm{mol}_{\mathrm{H} 2}$. The model is solved for each case and the results of the concentrations of aromatics in the liquid phase are summarized inTable 14.

Table 14: Concentration of aromatics in the feed and the product of the real plant and the simulation.

\begin{tabular}{|c|c|c|c|c|}
\hline & Product $_{\text {(plant) }}$ & $\begin{array}{l}\text { Product } \\
\Delta \mathbf{H}_{\text {poly }}=-30 \mathrm{~kJ} / \mathrm{mol} \\
\mathbf{H}_{2 \text { (base case) }}\end{array}$ & $\begin{array}{l}\Delta \mathrm{H}_{\text {poly }}=-45 \mathrm{~kJ} / \mathrm{mol} \\
\mathrm{H}_{2}\end{array}$ & $\begin{array}{l}\Delta H_{\text {poly }}=-60 \mathrm{~kJ} / \mathrm{mol} \\
\mathrm{H}_{2}\end{array}$ \\
\hline Sulfur wppm & 3.4 & 0.14 & 0.12 & 0.12 \\
\hline Mono wt \% & 18.6 & 18.9 & 20.9 & 21.0 \\
\hline Di wt $\%$ & 3.0 & 12.1 & 14.4 & 14.5 \\
\hline Poly wt \% & 0.4 & 3.4 & $7.8 \times 10^{-3}$ & $1.4 \times 10^{-5}$ \\
\hline
\end{tabular}

It is evident from Table 14 that the value of $\Delta \mathrm{H}_{\text {poly }}$ has a big impact on the concentrations of polyaromatics. A higher value of $\Delta \mathrm{H}_{\text {poly }}$ causes a significant shift in the equilibrium, promoting the hydrogenation of the polyaromatics (forward reaction in eq. (6)). The predicted concentration of sulfur in the outlet remains slightly lower (Figure 17(a)) compared to the industrial case. On the other hand, the temperature profiles with higher values of $\Delta \mathrm{H}_{\text {poly }}$ remain consistent and higher than the temperature profile of the base case, as expected (Figure 17(b)). This explains the higher concentration of di- and consequently monoaromatics (Figure 17(c)). The slightly smaller value compared to the base case is explained by the higher temperature caused by the saturation of di- and monoaromatics. However, with the available kinetic model, the concentration of polyaromatics 
decreases to unrealistic levels. Therefore, in order to achieve accurate predictions of concentrations of aromatics in the product, the value of $\Delta \mathrm{H}_{\text {poly }}$ and the kinetic model must be addressed carefully.

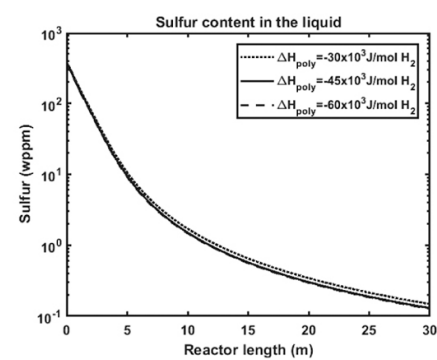

(A)

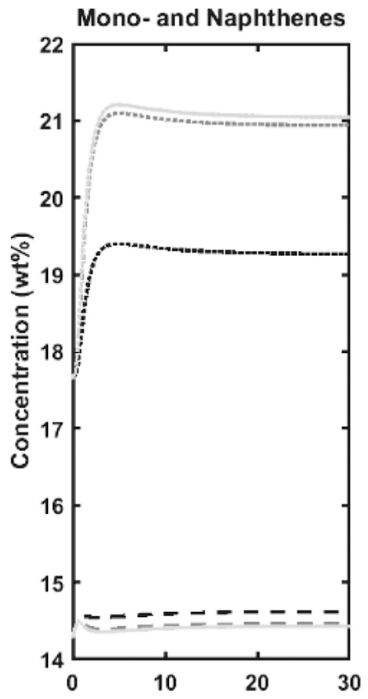

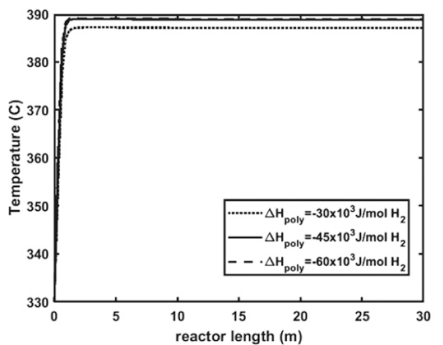

(B)

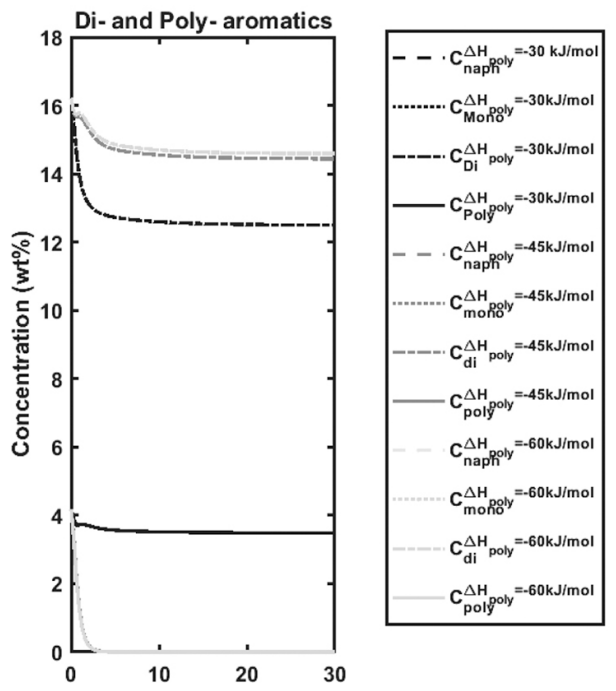

reactor length $(\mathrm{m})$

(C)

Figure 17: Simulations of (A) temperature profile of the liquid with a three different values of $\Delta \mathrm{H}_{\text {poly }}:$ : (1) $\Delta \mathrm{H}_{\text {poly }}=$ $-30 \mathrm{~kJ} / \mathrm{mol} \mathrm{H}_{2}$ (base case) $\Delta \mathrm{H}_{\text {poly }}=-45 \mathrm{~kJ} / \mathrm{mol} \mathrm{H}_{2}$ and (3) $\Delta \mathrm{H}_{\text {poly }}=-60 \mathrm{~kJ} / \mathrm{mol} \mathrm{H}_{2}$. (B) Organic sulfur content in the liquid phase across the length of the reactor with the three different values of $\Delta \mathrm{H}_{\text {poly }}$. (C) Concentration profiles of aromatics throughout the reactor.

Even though the simulations follow the trend of previous works, it is evident that more elaborate qualitative studies on the kinetics of the aromatics are missing in literature; hence, our predictive simulation is not able to reflect the actual HDA conversions of an industrial reactor. Experimental data are required to develop kinetics models that reflect more accurately the characteristics of the products of the hydrotreating unit. In addition to the kinetic studies and for further investigations, accounting for vaporization of the pseudo-components and quench zones would likely be important steps to obtain predictions closer to the industrial reality.

\section{Conclusions}

In this work, a model for a trickle-bed reactor has been developed and its application is demonstrated on an industrial hydrotreating unit using a practical definition of lumps of aromatic groups in terms of pseudocomponents with their own boiling point curves. Two different modelling approaches (i) assuming constant gas velocity and (ii) variable gas velocity were evaluated. From a modelling consistency point of view, a variable gas velocity should always be used. However, the use of pseudo-components to simulate a petroleum stream is a source of error in the mass balance bigger than the error of using a variable gas velocity as opposed to a constant one. Furthermore, the available kinetic models found in literature lead to a slight over prediction in the concentration of organic sulfur at the outlet of the reactor. On the other hand, the prediction of the concentration of each group of aromatics is over predicted when comparing to the data of the plant, however, the trends on the behavior of reactants is consistent with cases studied in literature. Nevertheless, the kinetic 
model must be improved to be able describe the saturation reactions and should be considered for further investigations.

In order to identify the most sensitive model parameters and input variables, a sensitivity analysis using the Morris-screening method was carried out. When focusing on the outlet temperature of the liquid and the outlet concentration of organic sulfur, mono-, di-, and polyaromatics as the variables of interest, the Morris screening method shows that the most sensitive parameters and input variables are the inlet temperature, and the pressure correction of the kinetic model for aromatics saturation. Therefore, a set of model evaluations were carried out to investigate the effect of different values associated with the inlet temperature, the pressure correction of the kinetic model of aromatics saturation. The inlet temperature dictates how fast the reactions take place and the aromatics reach equilibrium. Unsurprisingly, the inlet temperature has also an effect on the outlet concentration of organic sulfur with lower values obtained at higher temperatures. The correction for pressure of the kinetic model of aromatic saturation has an effect on both, the outlet temperature and the organic sulfur concentration due to the rate and magnitude of the heat released by the saturation reactions. The equilibrium concentration of each of the aromatics is also affected and it can be a fine-tuning parameter in order to describe more accurately the outlet concentration of aromatics. Preferably, an adequate aromatics saturation kinetics model should be used and/or developed.

A model performance study was performed to observe the effect of the excess of hydrogen on the organic sulfur concentration of the outlet. At higher $\mathrm{H}_{2}$ / oil ratios, higher conversions of BT and DBT-type compounds is obtained as expected. Finally, a model performance study was carried out to investigate the effect of the value of $\Delta \mathrm{H}_{\text {poly }}$. The kinetic model of polyaromatics is not able to predict realistic values of concentration of polyaromatics when using typical values of $\Delta \mathrm{H}_{\text {poly }}$ available in literature, because higher values of $\Delta \mathrm{H}_{\text {poly }}$, cause the concentration of polyaromatics go to zero. Therefore, a more accurate kinetic model of aromatic saturation is needed to predict qualitatively the outlet stream of a real large-scale hydrotreating unit.

This paper discloses the most influential parameters of the operation of a hydrotreating unit. The outcome of this work can be beneficial for hydrotreating units that are currently operating. However, there are different variables that are a source of uncertainties and might be addressed in future work. For instance, the liquid maldistribution is a characteristic of the reactor design. Liquid maldistribution usually leads to unpredictable and uncontrollable reactor performance at large scale. Therefore, different variables must be taken into account, such as catalyst packing, number, size and location of the reactor beds.

\section{List of symbols}

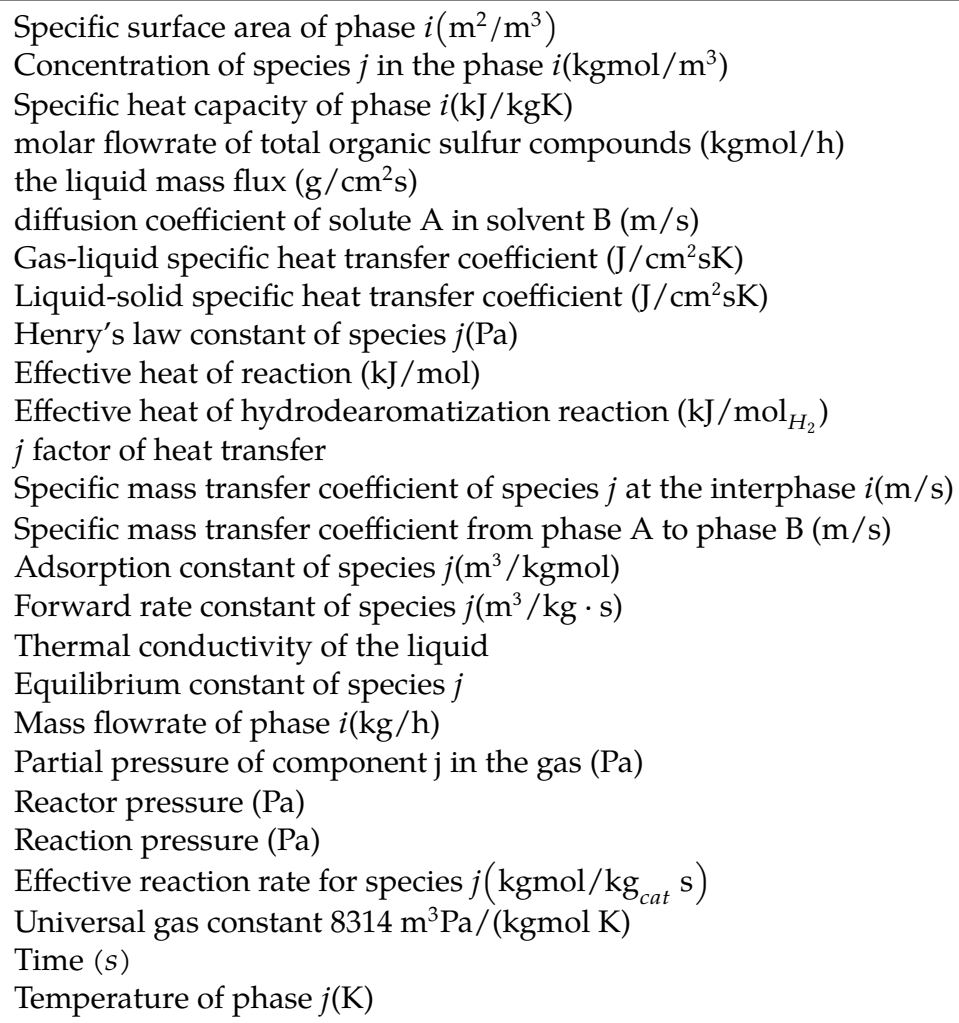




\section{$u_{j} \quad$ Axial velocity of phase $(\mathrm{m} / \mathrm{s})$}

$V_{B} \quad$ Molecular volume of the solute $\left(\mathrm{m}^{3} / \mathrm{kgmol}\right)$

$x_{A r-S} \quad$ Conversion of organic sulfur compounds

\section{Greek letters}

$\varepsilon_{G} \quad$ Volume fraction of gas $\left(\mathrm{m}^{3} / \mathrm{m}^{3}\right.$ reactor $)$

$\varepsilon_{L} \quad$ Volume fraction of liquid $\left(\mathrm{m}^{3} / \mathrm{m}^{3}\right.$ reactor $)$

$\varepsilon_{S} \quad$ Volume fraction of solid $\left(\mathrm{m}^{3}\right.$ catalyst particle $\left./ \mathrm{m}^{3}{ }_{\text {reactor }}\right)$

$\varepsilon_{\text {cat }} \quad$ Volume fraction of catalyst $\left(\mathrm{m}^{3}\right.$ catalyst particle $/ \mathrm{m}^{3}$ reactor $)$

$\varepsilon_{\text {pores }} \quad$ Volume fraction of the catalyst pores $\left(\mathrm{m}^{3}\right.$ catalyst particle $/ \mathrm{m}^{3}$ reactor $)$

$v_{j} \quad$ Molar volume of species $j\left(\mathrm{~m}^{3} / \mathrm{kgmol}\right)$

$\mu_{L} \quad$ Viscosity of the liquid at given $\mathrm{T}$ and $\mathrm{P} .(\mathrm{Pa} / \mathrm{s})$

$\rho_{j} \quad$ Density of the gas at given temperature and pressure $\left(\mathrm{kg} / \mathrm{m}^{3}\right)$

$\rho_{\text {cat }} \quad$ Density of the catalyst $\left(\mathrm{kg}_{\text {catalyst }} / \mathrm{m}^{3}\right.$ catalyst particle $)$

$\rho_{S} \quad$ Density of the solid phase $\left(\mathrm{kg}_{\text {wet catalyst }} / \mathrm{m}^{3}\right.$ reactor $)$

\section{References}

Al-Dahhan, M.H., F. Larachi, M.P. Dudukovic, and A. Laurent. 1997. “High-Pressure Trickle-Bed Reactors, a Review." Industrial and Engineering Chemistry Research 36: 3292-314.

Alvarez, A., and J. Ancheyta. 2012. "Transient Behaviour of Residual Oil Front-End Hydrodemetallization in a Trickle-Bed Reactor." Chemical Engineering Journal 197: 204-14.

Alvarez, A., L., C. Castañeda, and ]. Ancheyta. 2014. “On the Application of Petroleum Feedstock Modeling Techniques for Developing Molecule-Based Models of Hydrocarbon Conversion Processes." Catalysis Today 222: 198-207.

Alvarez-Majmutov, A., and ] Chen. 2014. "Modelling and Simulation of a Multibed Industrial Hydrotreater with Vapor-Liquid Equilibrium." Industrial and Engineering Chemistry Research 53: 10566-10575.

Bhaskar, M., G. Valavarasu, B. K. Sairam, S. Balaraman, and K. Balu. 2004. “Three-Phase Reactor Model to Simulate the Performance of PilotPlant and Industrial Trickle-Bed Reactors Sustaining Hydrotreating Reactions." Industrial and Engineering Chemistry Research 43: 6654-69.

Boelhouwer, J.G. 2001. Nonsteady Operation of Trickle-Bed Reactors: Hydrodynamics, Mass and Heat Transfer. Eindhoven: Technische Universiteit Eindhoven. DOI: 10.6100/IR549731.

Carberry, J. 1976. Chemical and Catalytic Reaction Engineering. New York: McCraw-Hill.

Chen, J., V. Mulgundmath, and N. Wang. 2011. "Accounting for Vapor-Liquid Equilibrium in the Modeling and Simulation of a Commercial Hydrotreating Reactor." Industrial and Engineering Chemistry Research 50: 1571-79.

Chowdhury, R., E. Pedernera, and R. Reimert. 2002. “Trickle-Bed Reactor Model for Desulfurization and Dearomatization of Diesel." AIChE Journal 48: 1 .

Collins, G.M., R.K. Hess, and A. Akgerman. 1985. "An Analytical Solution for a Tubular Reactor Model with Dispersion in Both Radial and Axial Directions." Chemical Engineering Communication 35: 281-91.

El-Hisnawi, A. A. 1981. “Tracer and Reaction Studies in Trickle-Bed Reactors.” ACS Symposium Series 196.

Feng, Xian., D Li, J. Chen, M. Niu, X. Liu, Lester Lik Teck Chan, and W. Li,. 2018. "Kinetic Parameter Estimation and Simulation of Trickle-Bed Reactor for Hydrodesulfurization of Whole Fraction Low-Temperature Coal Tar." Fuel 230: 113-25.

Goto, S., and J. M. Smith. 1975. “Trickle-Bed Reactor Performance: I. Holdup and Mass Transfer Effects.” AlChE Journal 21: 706.

Ho, T.C. 2008. "Kinetic Modeling of Large-Scale Reaction Systems Catalysis Reviews." Science and Engineering 50: 287-378.

Iserles, A. 2009. A First Course in the Numerical Analysis of Differential Equations, 2nd edn. Cambridge, United Kingdom: Cambridge University Press.

Khadilkar, M.R., M.P. Dudukovic, and P.L. Mills. 1998. “Trickle-Bed Reactor Models for Systems with a Volatile Liquid Phase.” Chemical Engineering Science 53: 2421-31 ISCRE'15 Proceedings.

Korsten, H., and U. Hoffmann. 1996. “Three-Phase Reactor Model for Hydrotreating in Pilot Trickle-Bed Reactors." AlChEJournal 42: 1350-60.

Latz, J., R. Peters, J. Pasel, L. Datsevich, and A. Jess. 2008. "Hydrodesulfurization of Jet-Fuel by Pre-Saturated One-Liquid-Flow Technology for Mobile Fuel Cell Applications." Chemical Engineering Science 64: 288-93.

Mederos, F.S., and ]. Ancheyta. 2007. “Mathematical Modeling and Simulation of Hydrotreating Reactors: Cocurrent versus Countercurrent Operations." Applied Catalysis A: Ceneral 332: 8-21.

Melli, T. R., J. M. de Santos, W. B. Kolb, and L. E. Scriven. 1990. “Cocurrent Downflow in Networks of Passages. Microscale Roots of Macroscale Flow Regimes." Industrial and Engineering Chemistry Research 29: 2367-79.

Morris, MD. 1991. “Factorial Sampling Plans for Preliminary Computational Experiments." Technometrics 33: 161-74.

Patil, R.C., P. Patra, A. Gupta, and A. Das. 2017. “Effect of Reactor Configuration on Performance of Vacuum Gas Oil (VCO) Hydrotreater: Modelling Studies." Computers and Chemical Engineering 104: 89-106.

Rajashekharam, M. V., R. Jaganathan, and R. Chaudhari. 1998. “Trickle-Bed Reactor Model for Hydrogenation of 2, 4 Dinitrotoluene: Experimental Verification." Chemical Engineering Science. 53: 787-805.

Ruzika, J., and J. Hanika. 1994. "Partial Wetting and Forced Reaction Mixture Transition in a Model Trickle-Bed Reactor." Catalysis Today 20: 467-83.

Sbaaei, E.S., and T.S. Ahmed. 2018. “Predictive Modeling and Optimization for an Industrial Coker Complex Hydrotreating Unit - Development and a Case Study." Fuel 212: 61-76.

Silva, J.D., A. Knoechelmann, and S.A. Lucena. 2006. "Trickle-Bed Reactor Modelling for Catalyst Hydrogenation with Partially Wetted Catalyst Particle." Chisa 2006-17th International Congress of Chemical and Process Engineering. 
Smith, G. D. 1978. Numerical Solution of Partial Differential Equations: Finite Difference Methods. Clarendon Press: Oxford, G.B.

Tarhan, M.O. 1983. Catalytic Reactor Design. New York: McGraw-Hill.

Tsochatzidis, N.A, and A.J. Karabelas. 1994. "Experiments in Trickle Beds at the Micro- and Macroscale. Flow Characterization and Onset of Pulsing." Engineering Chemical Research 33: 1299-309.

Van Krevelen, D. W., and J. T. Krekels. 1948. "Rate of Dissolution of Solid Substances. Part I.: Physical Dissolution Rec." Travaux Chimiques 67: 512.

Yan, T.Y. 1980. “Dynamics of a Trickle Bed Hydrocracker with a Quenching System.” Canadian Journal ofChemical Engineering 58: 259. 